\title{
Actin-related protein 5 functions as a novel modulator of MyoD and MyoG in skeletal muscle and in rhabdomyosarcoma
}

\author{
Tsuyoshi Morita ${ }^{1} *$ and Ken'ichiro Hayashi ${ }^{2}$ \\ ${ }^{1}$ Department of Biology, Wakayama Medical University, 580 Mikazura, Wakayama, \\ 641-0011, Japan \\ ${ }^{2}$ Department of RNA Biology and Neuroscience, Osaka University Graduate School \\ of Medicine, 2-2 Yamadaoka, Suita, Osaka 565-0871, Japan \\ * Corresponding author: Tsuyoshi Morita \\ E-mail: tsuyo@wakayama-med.ac.jp \\ Tel.: +81-73-447-2300 \\ Fax.: +81-73-446-6720
}




\section{Abstract}

2 Myogenic regulatory factors (MRFs) are pivotal transcription factors in myogenic 3 differentiation. MyoD commits cells to the skeletal muscle lineage by inducing 4 myogenic genes through recruitment of chromatin remodelers to its target loci. This 5 study showed that Actin-related protein 5 (Arp5) acts as an inhibitory regulator of

6 MyoD and MyoG by binding to their cysteine-rich (CR) region, which overlaps with the

7 region essential for their epigenetic functions. Arp5 expression was faint in skeletal 8 muscle tissues. Excessive Arp5 in mouse hind limbs caused skeletal muscle fiber

9 atrophy. Further, Arp5 overexpression in myoblasts inhibited myotube formation by 10 diminishing myogenic gene expression, whereas Arp5 depletion augmented myogenic 11 gene expression. Arp5 disturbed MyoD-mediated chromatin remodeling through 12 competition with the three-amino-acid-loop-extension-class homeodomain transcription

13 factors the Pbx1-Meis1 heterodimer for binding to the CR region. This antimyogenic

14 function was independent of the INO80 chromatin remodeling complex, although Arp5

15 is an important component of that. In rhabdomyosarcoma (RMS) cells, Arp5 expression 16 was significantly higher than in normal myoblasts and skeletal muscle tissue, probably 17 contributing to MyoD and MyoG activity dysregulation. Arp5 depletion in RMS 18 partially restored myogenic properties while inhibiting tumorigenic properties. Thus, 19 Arp5 is a novel modulator of MRFs in skeletal muscle differentiation.

\section{Introduction}

22 Actin-related protein 5 (Arp5), encoded by Actr5, is a nuclear-localized actin-like 23 protein (Schafer and Schroer, 1999). Studies have investigated the role of Arp5 in the 24 nucleus as one of the subunits of the ATPase-dependent chromatin remodeling complex 
INO80 (Shen et al., 2000). INO80 regulates various DNA metabolic processes, such as gene expression, DNA replication, and DNA repair by nucleosome sliding (Polil et al., 2017). It contains $\beta$-actin and three Arp family members (Arp4, Arp5, and Arp8). Arp5 forms the Arp5 module with Ies6 (encoded by Ino80c), which is necessary for ATP hydrolysis and nucleosome sliding by INO80 (Yao et al., 2015). However, a few features of Arp5 are unrelated to INO80. In Arabidopsis, Arp5 and Ino80, an essential ATPase component of INO80, have common and distinct features in plant growth and development (Kang et al., 2019). In addition, Arp5 plays an INO80-independent role in regulating the differentiation of vascular smooth muscle cells (SMCs) (Morita et al., 2014). In rat SMCs, Arp5 expression is strongly inhibited, although INO80 activity is generally necessary for cell growth and proliferation. Arp5 inhibits SMC differentiation by interacting with and inhibiting the SAP family transcription factor myocardin, which is a key regulator for the induction of SMC-specific contractile genes, indicating that low Arp5 expression in SMCs contributes to maintaining their differentiation status. In contrast, in cardiac and skeletal muscles, although Apr5 expression is low, its physiological significance is unclear.

Myogenic regulatory factors (MRFs), such as MYF5, MyoD, MyoG, and MRF4, are skeletal-muscle-specific basic helix-loop-helix (bHLH) transcription factors and master regulators of skeletal muscle development. They recognize a cis-regulatory element

44 E-box, usually found in promoter and enhancer regions of muscle-specific genes, as a heterodimer with ubiquitous bHLH proteins of the E2A family (E12 and E47) (Funk et al., 1991). MRFs enhance the transcriptional activity of myogenic genes via chromatin remodeling by recruiting the switch/sucrose nonfermentable (SWI/SNF) complex to previously silent target loci (Roy et al., 2002; Ohkawa et al., 2007). This epigenetic 
49 activity depends on a histidine- and cysteine-rich (H/C) region N-terminal to the bHLH

50 domain in MRFs (Gerber et al., 1997). This region contains a CL-X-W motif, which is a

51 binding site for the heterodimer of three-amino-acid-loop-extension (TALE)-class

52 homeodomain transcription factors (Pbx1 and Meis/Prep1) (Knoepfler et al., 1999).

53 Funk and Wright (1992) reported that E-box elements recognized by MyoG are occasionally flanked by a novel consensus motif TGATTGAC, which was also identified as a binding motif for the Pbx1-Meis/Prep1 heterodimer (Knoepfler et al., 1999). Thus, MRFs form a complex with the TALE heterodimer on DNA, leading to the recruitment of chromatin remodelers and an increase in the accessibility of their target 58 loci.

This study reported a novel role of Arp5 in myogenic differentiation of skeletal muscle cells. We identified Arp5 as an inhibitory binding protein for MyoD and MyoG

61 in skeletal muscle and rhabdomyosarcoma (RMS) cells. Results showed that Arp5 competes with the Pbx1-Meis1 heterodimer for interaction with the cysteine-rich (CR) region of MyoD and MyoG and consequently inhibits myogenic differentiation.

\section{Results}

\section{Arp5 prevents skeletal muscle development by inhibiting MRF expression}

67 Arp5 expression was significantly low in heart, aorta, and especially, hind limb muscle

68 tissues (Figure 1A). Besides, Arp5 expression in primary mouse myoblasts significantly

69 decreased with myotube differentiation (Figure 1B). The public human transcriptome databases (Human Protein Atlas [HPA], Genotype-Tissue Expression [GTEx], and Functional Annotation of the Mouse/Mammalian Genome 5 [FANTOM5]) showed low 

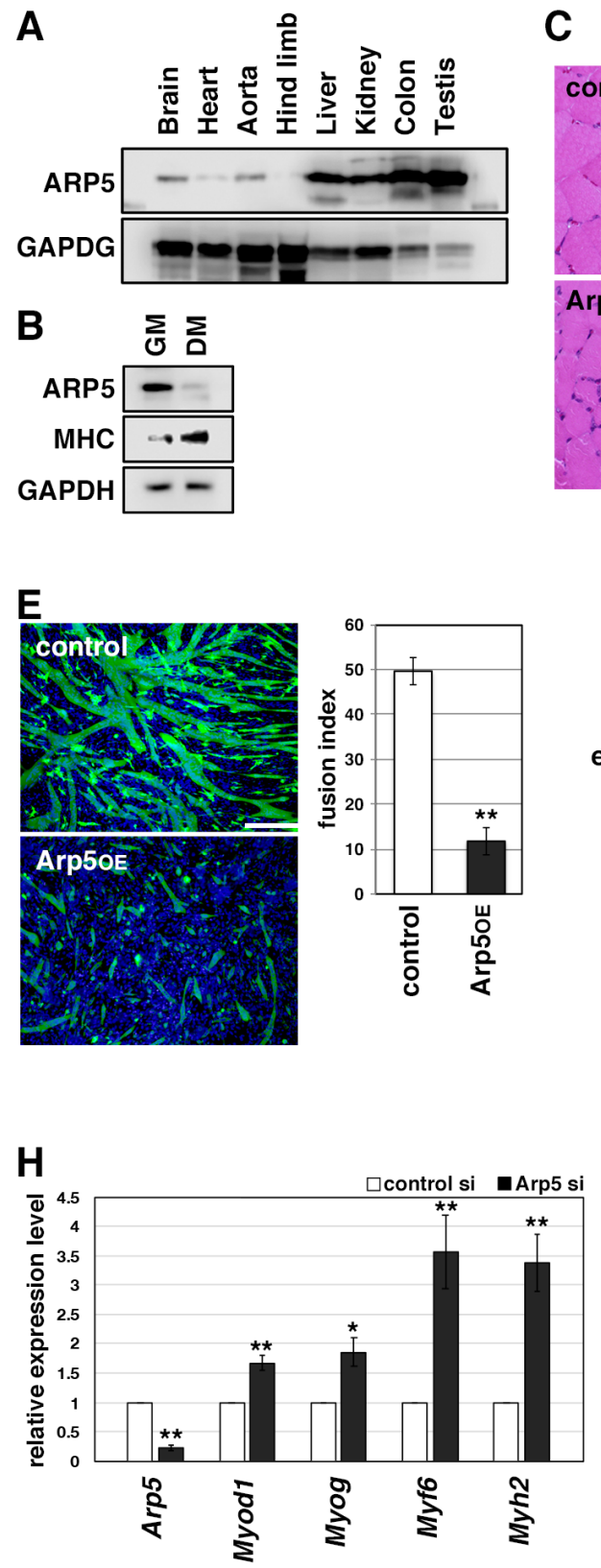

C
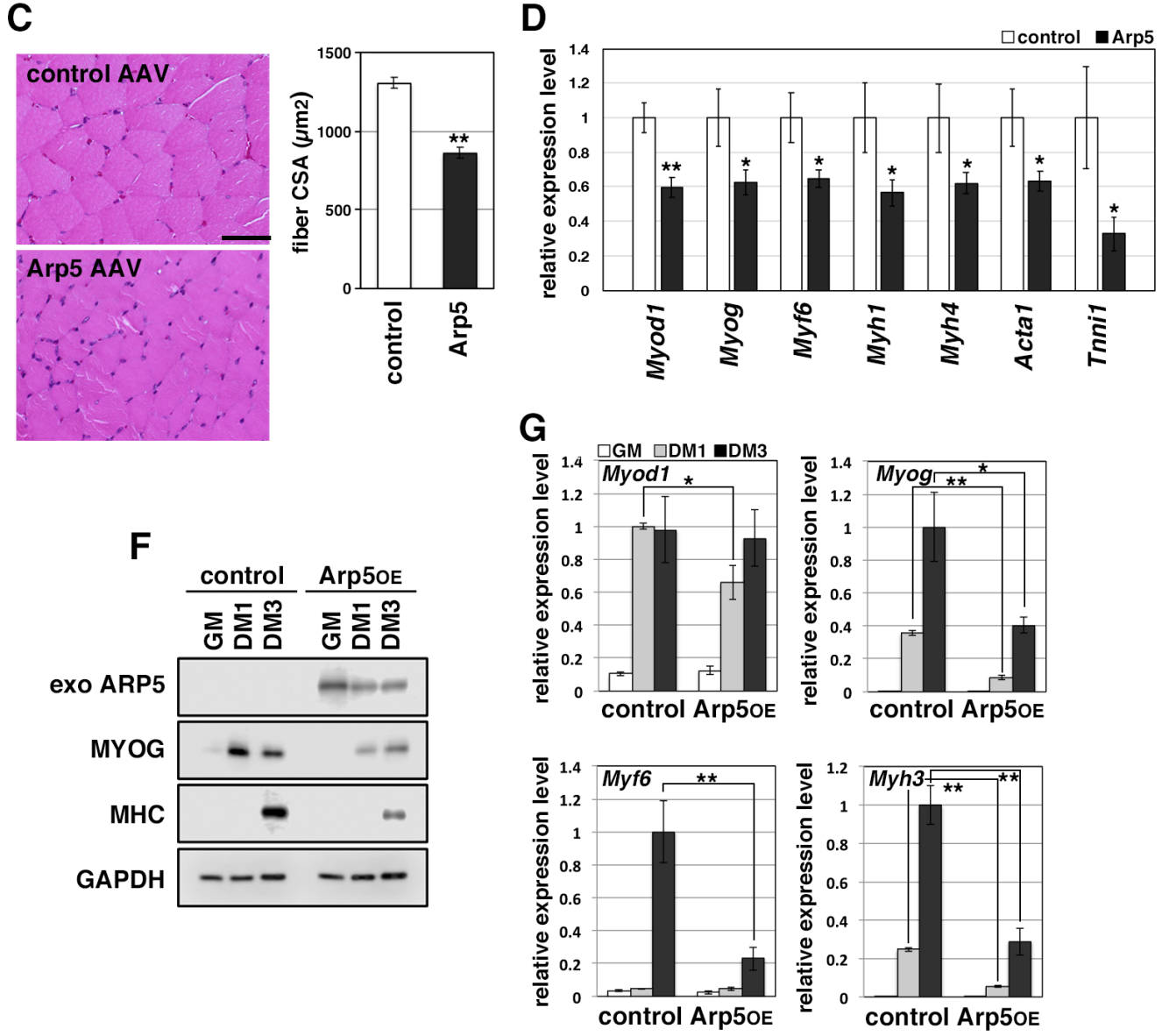
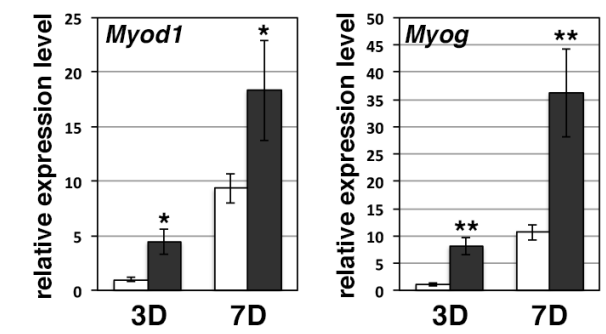

Figure 1. Actin-related protein 5 (Arp5) inhibits skeletal muscle differentiation. (A) Arp5 expression in mouse tissues. (B) Arp5 and myosin heavy chain (MHC) expression in C2C12 cells cultured in growth medium (GM) or differentiation medium (DM). (C) Representative images of hematoxylin and eosin (H\&E)-stained section of the hind limb muscle from mice injected with control or Arp5-AAV6 vector (left). Scale bar $=50 \mu \mathrm{m}$. Muscle fiber cross-sectional area (CSA) measured in 190 fibers and statistically analyzed (right). (D) Myogenic gene expression in AAV6-vector-injected hind limb muscles. (E) Representative fluorescence images of differentiated $\mathrm{C} 2 \mathrm{C} 12$ cells transfected with green fluorescent protein (GFP) alone (control) or together with Arp5 (Arp5 ${ }^{\mathrm{OE}}$ ) (left). Nuclei were visualized by Hoechst 33342. Scale bar $=100 \mu \mathrm{m}$. The fusion index was measured on 22 images and statistically analyzed (right). (F) Myogenic protein expression in C2C12 cells transfected with control or Arp5 expression vector. The cells were cultured in GM or DM for 1 day (DM1) or 3 days (DM3) after transfection. (G) Myogenic gene expression in Arp5-transfected C2C12 cells. (H) Myogenic gene expression in mouse primary myoblasts transfected with control or Arp5 short interfering RNA (siRNA). (I) Myogenic gene expression in 10T1/2 cells treated with 5-azacytidine. The cells were transfected with control or Arp5 siRNA prior to 5azacytidine treatment. All statistical data are presented as the mean \pm standard error of the mean (SEM). $* P<0.05, * * P<0.01$ (Student's $t$-test). 

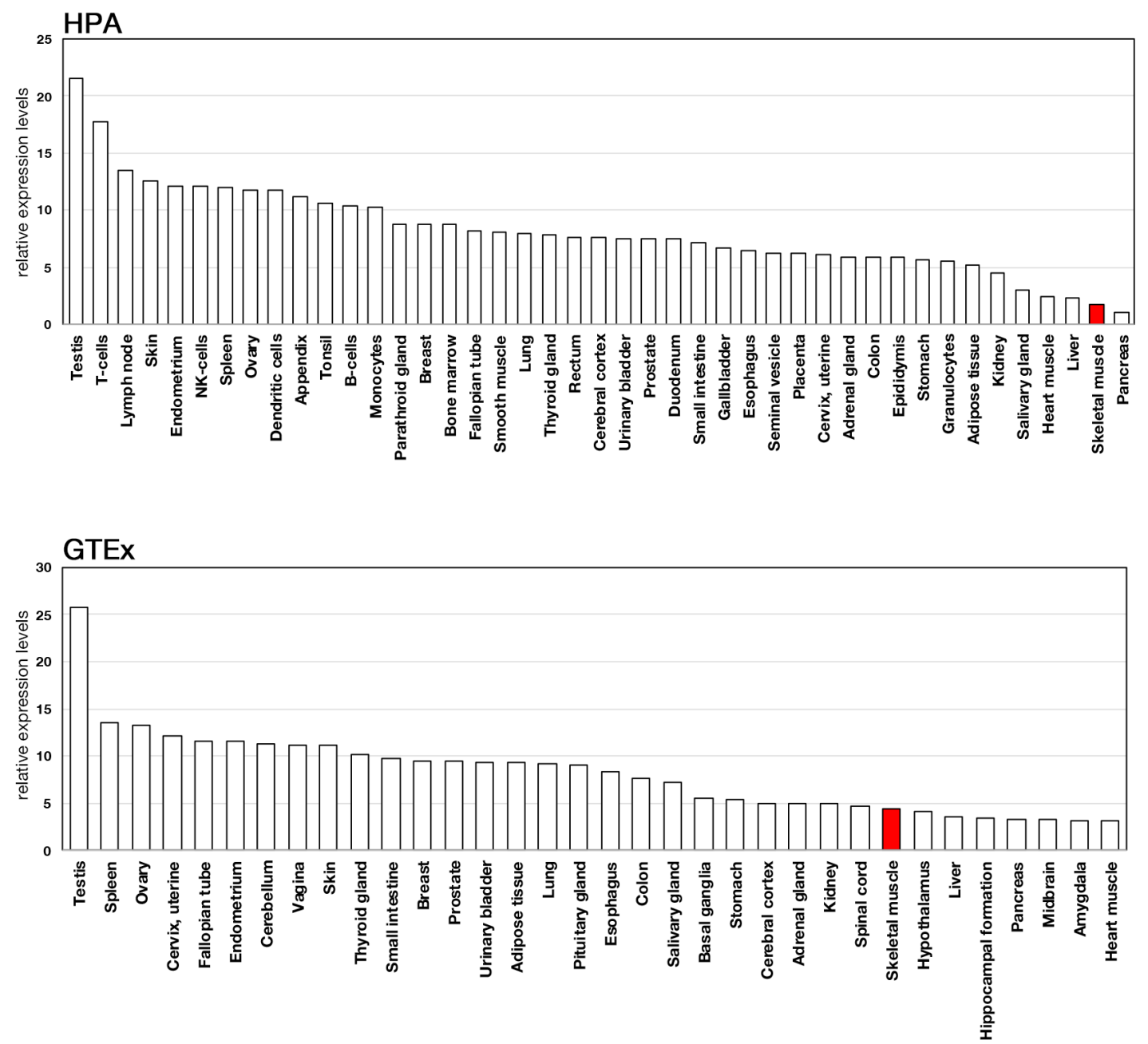

FANTOM5

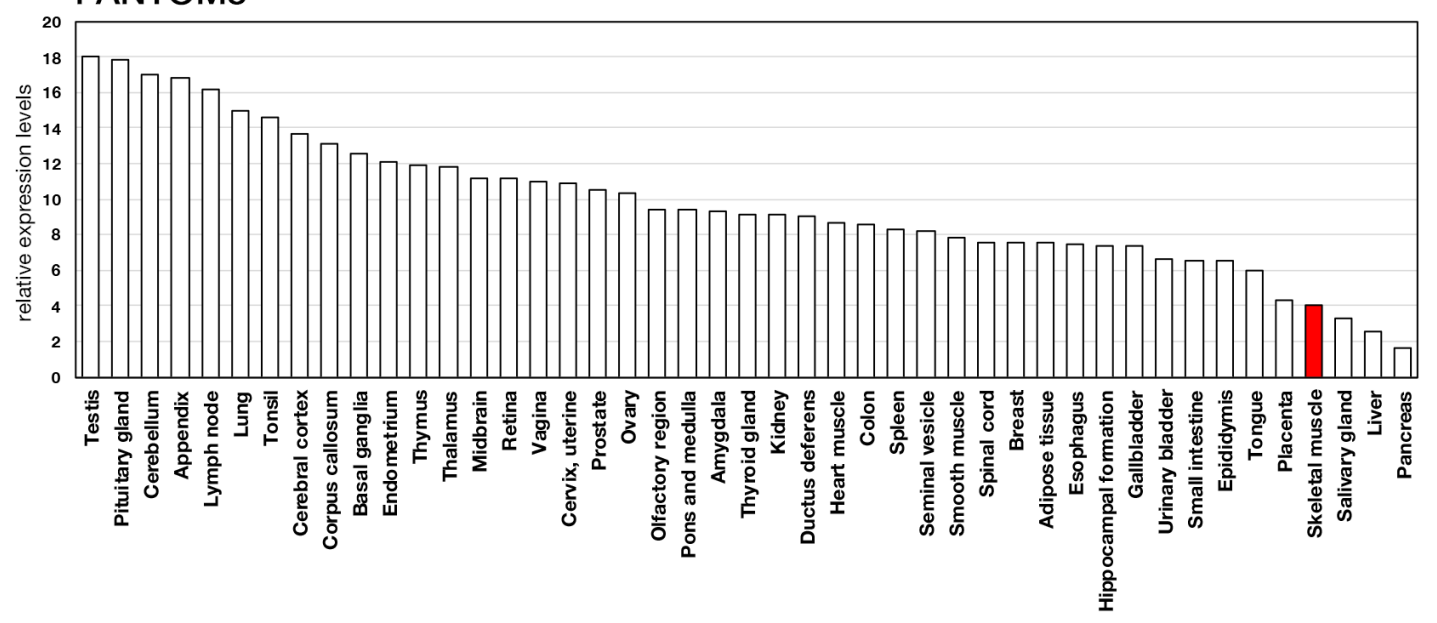

Figure 1-figure supplement 1. Expression profiles of Actin-related protein 5 (ARP5) in human tissues. Expression data of ARP5 were acquired from three public databases: Human Protein Atlas (HPA), Genotype-Tissue Expression (GTEx), and Functional Annotation of the Mouse/Mammalian Genome 5 (FANTOM5). 

significantly reduced compared to the control group (Figure 1C). In these atrophic muscles, gene expression levels of MRFs (Myod1, MyoG, and Myf6) significantly decreased, accompanied by a decrease in other skeletal muscle markers, such as Myh4, Actal, and Tnnil (Figure 1D).

In $\mathrm{C} 2 \mathrm{C} 12$ cells, Arp5 overexpression significantly inhibited the fusion ability of myoblasts and the induction of MyoG and myosin heavy chain (MHC) under the conditions for myotube formation (Figure 1E,F). In addition, the induction of Myodl, MyoG, Myf6, and Myh3 was also significantly inhibited (Figure 1G). Conversely, gene silencing of Arp5 by short interfering RNA (siRNA) (Arp5-si) increased MRF and Myh2 expression (Figure 1H). into differentiated skeletal muscle cells with the induction of endogenous MRF expression (Davis et al., 1987). There was significant induction of endogenous Myodl and $M y o G 7$ days after 5-azacytidine treatment, and Arp5 silencing significantly augmented Myodl and MyoG induction (Figure 1I). These findings show that Arp5 plays an inhibitory role in skeletal muscle development via regulating MRF expression and activity.

High Arp5 expression contributes to defective myogenic differentiation in rhabdomyosarcoma

RMS is a common soft-tissue sarcoma developed from skeletal muscle with defective myogenic differentiation. High MyoD and MyoG expression is used in the clinical diagnosis of RMS, but they are not fully active for the induction of their target genes 
97 (Folpe 2002; Keller and Guttridge 2013). ARP5 expression was significantly higher in

98 human embryonal and alveolar RMS tissues compared with healthy and tumor-adjacent

99 skeletal muscles (Figure 2A) and in RD cells compared with primary human myoblasts

100 (Figure 2B), indicating that Arp5 overexpression contributes to MRF dysfunction in 101 RMS.

102 Microarray analysis on Arp5-silencing RD cells showed that Arp5-si increased the 103 expression of numerous genes involved in muscle function and development (Figure 104 2C,D, Figure 2-Table supplement 1). The increased myogenic gene expression was 105 also confirmed by real-time reverse transcription polymerase chain reaction (RT-PCR) 106 (Figure 2E). Unlike myoblasts, RD cells have little or no ability to form myotubes, even under serum-free culture conditions, but Arp5 depletion led RD cells to form numerous myotube-like structures with upregulation of myogenic marker proteins (Figure 2F).

Arp5 is one of the subunits of INO80, so siRNA (Ies6-si and Ino80-si) also depleted 110 the expression of other subunits (Ies6 and Ino80). The genes altered by the silencing of each of these partly overlapped (Figure2-figure supplement 1A,B); 39.2\% and 32.4\%

112 of the genes altered by Arp5-si overlapped with those altered by Ies6-si and Ino80-si, 113 respectively. Contrary to Arp5-si, however, Ies6-si and Ino80-si hardly increased the 114 expression of muscle-related genes (Figure 2C,E, Figure 2-figure supplement 1C-E).

115 These findings show that Arp5 overexpression inhibits the expression of muscle-related 116 genes and, therefore, terminal myogenic differentiation in RMS in an 117 INO80-independent manner.

119 Arp5 knockout leads to loss of tumorigenicity of RD cells

120 In Arp5-knockout RD (Arp5-KO) cells, a few nucleotides downstream of the start 
A

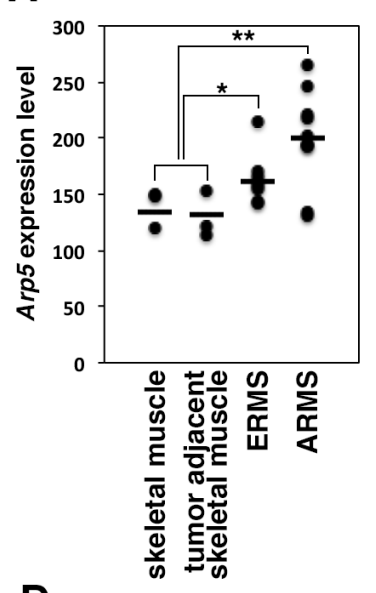

D
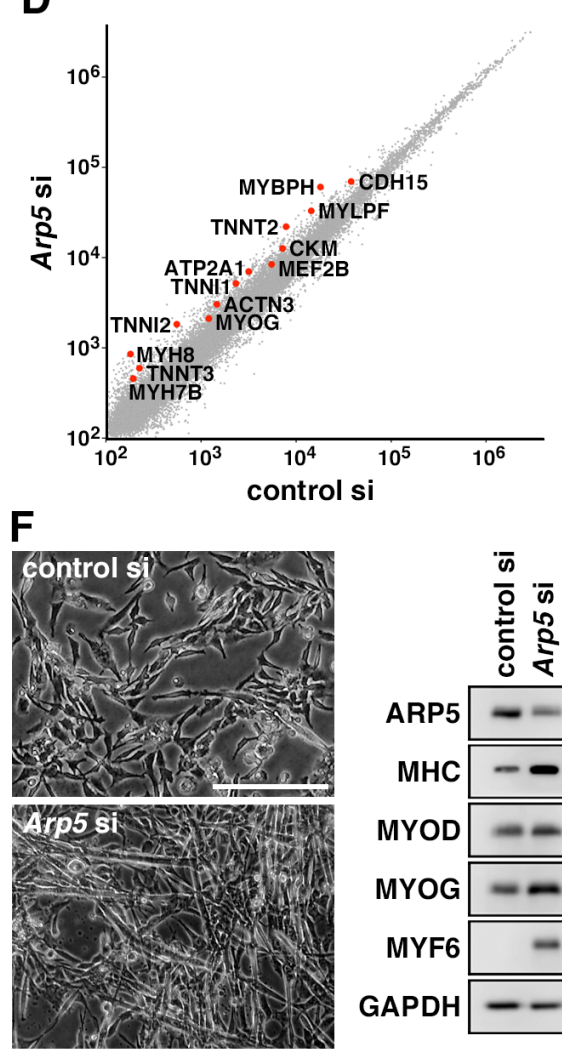

B

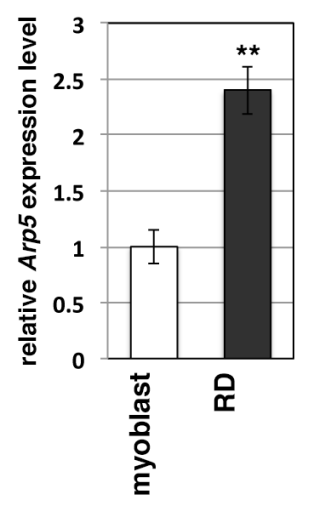

C

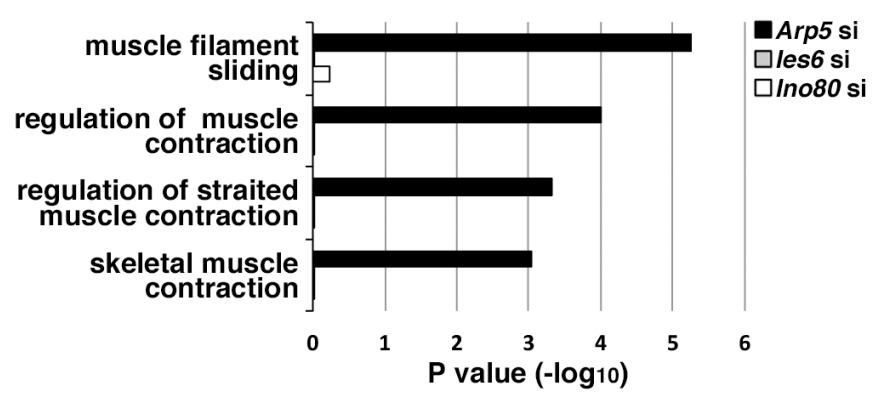

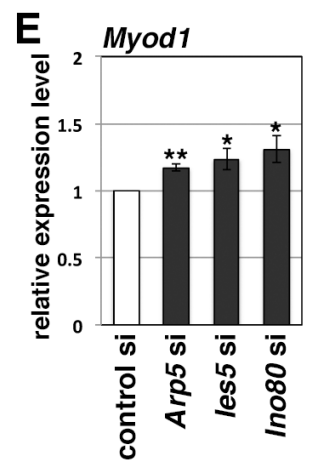
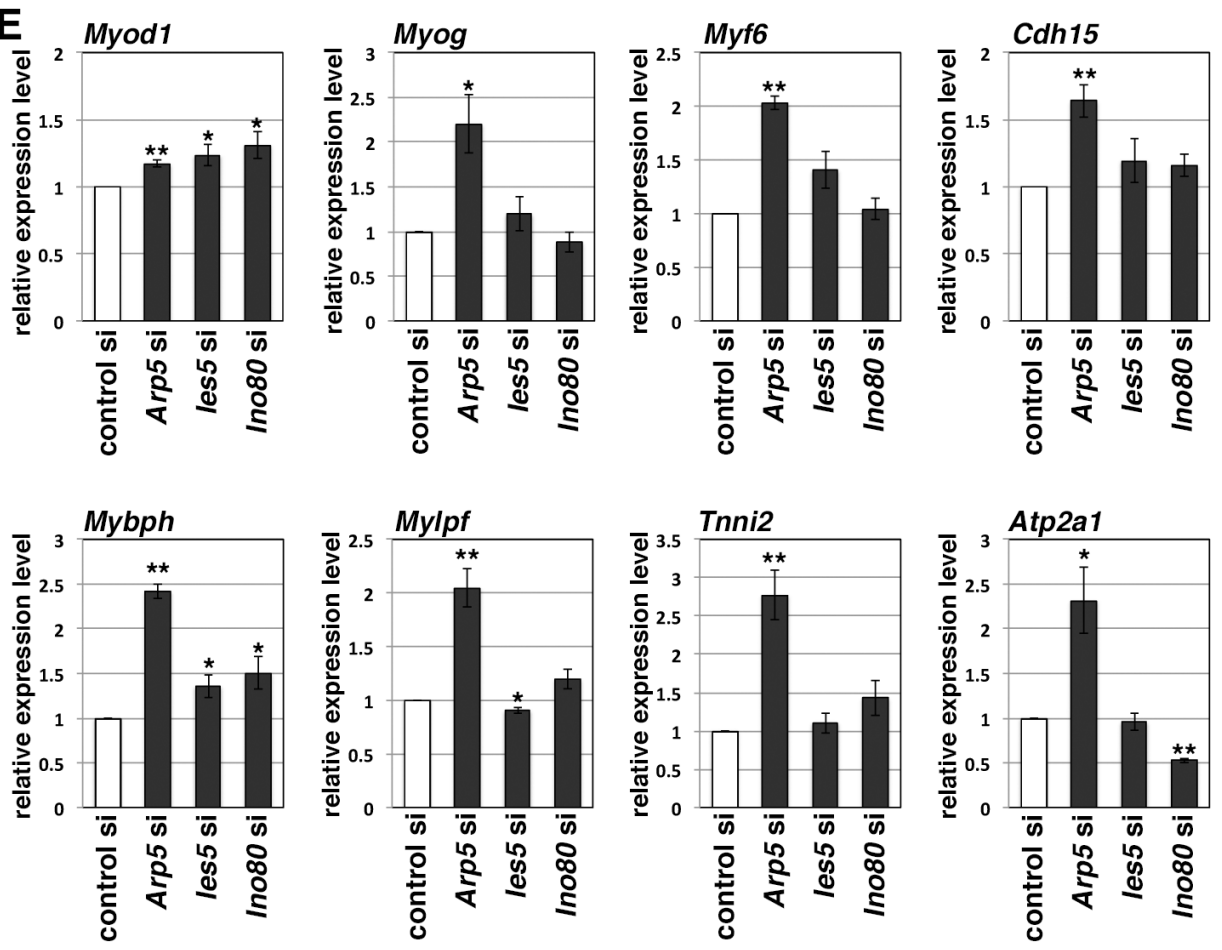

Figure 2. Actin-related protein 5 (Arp5) knockdown increases myogenic gene expression in rhabdomyosarcoma (RMS) cells. (A) Arp5 expression in normal skeletal muscle, tumor-adjacent skeletal muscle, embryonal RMS (ERMS), and aveolar RMS (ARMS). Bars indicate average expression levels. (B) ARP5 expression in human primary myoblasts and RD cells. (C) Enrichment analysis of muscle-related Gene Ontology terms from DNA microarray data on comparison between control-si and Arp5-, Ies6-, or Ino80-si samples. (D) Scatter plot of gene expression level in control-si and Arp5-si RD cells. (E) Myogenic gene expression in control-, Arp5-, Ies6-, and Ino80-si RD cells. (F) Representative phase-contrast images of control-si and Arp5-si RD cells (left). Scale bar $=100 \mu \mathrm{m}$. Myogenic protein expression in these cells (right). All statistical data are presented as the mean \pm standard error of the mean (SEM). ${ }^{*} P<0.05$, $* * P<0.01$ (Student's $t$-test). 


\begin{tabular}{|c|r|r|r|}
\cline { 2 - 4 } \multicolumn{1}{c|}{} & \multicolumn{3}{c|}{ relative expression level (vs control siRNA) } \\
\hline gene name & Arp5 siRNA & les siRNA & Ino80 siRNA \\
\hline ACTN3 & 2.076003774 & 0.687842617 & 0.938970893 \\
\hline ATP2A1 & 2.212933663 & 0.64311357 & 0.418973526 \\
\hline CDH15 & 1.835053382 & 1.238002233 & 1.384500699 \\
\hline CKM & 1.747237254 & 0.743827933 & 0.996854717 \\
\hline MEF2B & 1.519753751 & 1.037254304 & 1.03429799 \\
\hline MYBPH & 3.366623852 & 1.222955635 & 1.993441588 \\
\hline MYH7B & 4.734458903 & 0.719439084 & 0.806704257 \\
\hline MYH8 & 2.644230776 & 1.950191916 & 0.185822279 \\
\hline MYLPF & 2.279431645 & 0.962704219 & 1.355377816 \\
\hline MYOG & 1.743530176 & 0.955793102 & 0.734200156 \\
\hline TNNI2 & 3.297109791 & 1.233338111 & 1.630513745 \\
\hline TNNT2 & 2.811110999 & 0.606930828 & 1.855443232 \\
\hline TNNT3 & 2.376308547 & 1.227166077 & 1.549523985 \\
\hline
\end{tabular}

Figure 2-Table supplement 1. List of the myogenic genes whose expression level is upregulated by Arp5 knockdown in RD cells 
A

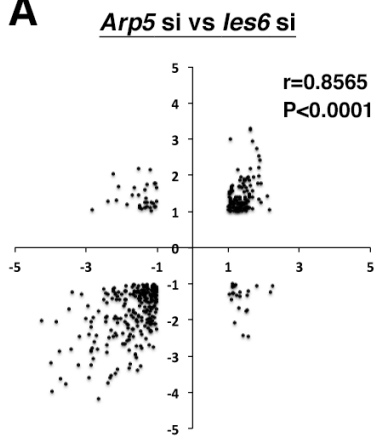

C

Ino80 siRNA

\begin{tabular}{|l|c|c|c|}
\hline \multicolumn{1}{|c|}{ term } & count & $\%$ & P value \\
\hline Mineral absorption & 10 & 1.5 & $1.40 \mathrm{E}-05$ \\
\hline Hypertrophic cardiomyopathy (HCM) & 12 & 1.8 & $6.30 \mathrm{E}-05$ \\
\hline TNF signaling pathway & 14 & 2.1 & $6.80 \mathrm{E}-05$ \\
\hline Dilated cardiomyopathy & 11 & 1.7 & $5.50 \mathrm{E}-04$ \\
\hline PI3K-Akt signaling pathway & 24 & 3.6 & $1.60 \mathrm{E}-03$ \\
\hline Focal achesion & 17 & 2.6 & $1.80 \mathrm{E}-03$ \\
\hline Legionellosis & 8 & 1.2 & $2.30 \mathrm{E}-03$ \\
\hline ECM-receptor interaction & 10 & 1.5 & $2.80 \mathrm{E}-03$ \\
\hline Regulation of actin cytoskeleton & 16 & 2.4 & $5.60 \mathrm{E}-03$ \\
\hline HTLV-I infection & 18 & 2.7 & $6.20 \mathrm{E}-03$ \\
\hline p53 signaling pathway & 8 & 1.2 & $7.70 \mathrm{E}-03$ \\
\hline Pathways in cancer & 24 & 3.6 & $8.10 \mathrm{E}-03$ \\
\hline Proteoglycans in cancer & 15 & 2.3 & $8.70 \mathrm{E}-03$ \\
\hline Cytokine-cytokine receptor interaction & 17 & 2.6 & $9.10 \mathrm{E}-03$ \\
\hline Insulin resistance & 10 & 1.5 & $1.20 \mathrm{E}-02$ \\
\hline Endocrine and other factor-regulated calcium reabsorption & 6 & 0.9 & $1.80 \mathrm{E}-02$ \\
\hline Inflammatory mediator regulation of TRP channels & 9 & 1.4 & $1.90 \mathrm{E}-02$ \\
\hline Ras signaling pathway & 15 & 2.3 & $2.30 \mathrm{E}-02$ \\
\hline Arrhythmogenic right ventricular cardiomyopathy (ARVC) & 7 & 1.1 & $2.70 \mathrm{E}-02$ \\
\hline Rheumatoid arthritis & 8 & 1.2 & $3.10 \mathrm{E}-02$ \\
\hline Platelet activation & 10 & 1.5 & $3.40 \mathrm{E}-02$ \\
\hline Non-alcoholic fatty liver disease (NAFLD) & 11 & 1.7 & $3.40 \mathrm{E}-02$ \\
\hline FoxO signaling pathway & 10 & 1.5 & $4.00 \mathrm{E}-02$ \\
\hline Cardiac muscle contraction & 7 & 1.1 & $4.30 \mathrm{E}-02$ \\
\hline Signaling pathways regulating pluripotency of stem cells & 10 & 1.5 & $5.10 \mathrm{E}-02$ \\
\hline MAPK signaling pathway & 15 & 2.3 & $5.20 \mathrm{E}-02$ \\
\hline Colorectal cancer & 6 & 0.9 & $6.10 \mathrm{E}-02$ \\
\hline Amoebiasis & 8 & 1.2 & $7.10 \mathrm{E}-02$ \\
\hline Oxytocin signaling pathway & 10 & 1.5 & $7.20 \mathrm{E}-02$ \\
\hline Hematopoietic cell lineage & 7 & 1.1 & $7.80 \mathrm{E}-02$ \\
\hline Osteoclast differentiation & 9 & 1.4 & $8.10 \mathrm{E}-02$ \\
\hline Malaria & 5 & 0.8 & $8.60 \mathrm{E}-02$ \\
\hline Ovarian steroidogenesis & 5 & 0.8 & $8.60 \mathrm{E}-02$ \\
\hline Complement and coagulation cascades & 6 & 0.9 & $8.70 \mathrm{E}-02$ \\
\hline
\end{tabular}

\section{D}

\section{Arp5 siRNA}

\begin{tabular}{|l|c|c|c|}
\hline \multicolumn{1}{|c|}{ term } & count & $\%$ & P value \\
\hline Systemic lupus erythematosus & 16 & 2.8 & $9.90 \mathrm{E}-06$ \\
\hline Alcoholism & 18 & 3.1 & $2.00 \mathrm{E}-05$ \\
\hline Regulation of actin cytoskeleton & 17 & 3 & $5.30 \mathrm{E}-04$ \\
\hline Hypertrophic cardiomyopathy (HCM) & 9 & 1.6 & $2.20 \mathrm{E}-03$ \\
\hline Cardiac muscle contraction & 8 & 1.4 & $6.90 \mathrm{E}-03$ \\
\hline Endocrine and other factor-regulated calcium reabsorption & 6 & 1 & $1.10 \mathrm{E}-02$ \\
\hline Dilated cardiomyopathy & 8 & 1.4 & $1.30 \mathrm{E}-02$ \\
\hline Pantothenate and CoA biosynthesis & 4 & 0.7 & $1.50 \mathrm{E}-02$ \\
\hline Focal adhesion & 13 & 2.3 & $2.00 \mathrm{E}-02$ \\
\hline Nitrogen metabolism & 3 & 0.5 & $9.00 \mathrm{E}-02$ \\
\hline
\end{tabular}
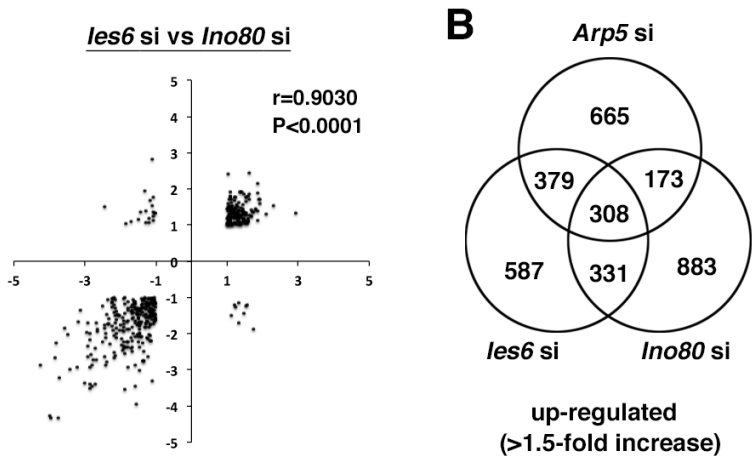

up-regulated (>1.5-fold increase)

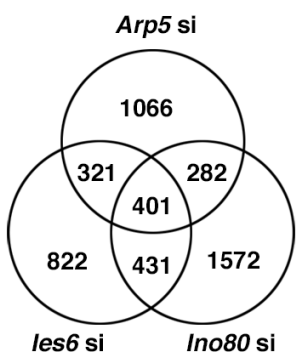

down-regulated (>1.5-fold decrease)

$\mathbf{E}$

Ies6 SiRNA
\begin{tabular}{|l|c|c|c|}
\hline \multicolumn{1}{|c|}{ term } & count & $\%$ & P value \\
\hline Alcoholism & 19 & 3.1 & $1.30 \mathrm{E}-05$ \\
\hline Systemic lupus erythematosus & 14 & 2.3 & $3.50 \mathrm{E}-04$ \\
\hline Viral carcinogenesis & 16 & 2.6 & $2.40 \mathrm{E}-03$ \\
\hline Endocrine and other factor-regulated calcium reabsorption & 7 & 1.2 & $2.90 \mathrm{E}-03$ \\
\hline p53 signaling pathway & 7 & 1.2 & $2.00 \mathrm{E}-02$ \\
\hline Insulin resistance & 9 & 1.5 & $2.20 \mathrm{E}-02$ \\
\hline Cell cycle & 9 & 1.5 & $4.60 \mathrm{E}-02$ \\
\hline ECM-receptor interaction & 7 & 1.2 & $6.00 \mathrm{E}-02$ \\
\hline FoxO signaling pathway & 9 & 1.5 & $6.60 \mathrm{E}-02$ \\
\hline Signaling pathways regulating pluripotency of stem cells & 9 & 1.5 & $8.10 \mathrm{E}-02$ \\
\hline PI3K-Akt signaling pathway & 17 & 2.8 & $8.90 \mathrm{E}-02$ \\
\hline Cytokine-cytokine receptor interaction & 13 & 2.1 & $9.10 \mathrm{E}-02$ \\
\hline Legionellosis & 5 & 0.8 & $9.40 \mathrm{E}-02$ \\
\hline Jak-STAT signaling pathway & 9 & 1.5 & $9.50 \mathrm{E}-02$ \\
\hline Phosphatidylinositol signaling system & 7 & 1.2 & $9.50 \mathrm{E}-02$ \\
\hline
\end{tabular}

$F$

cancer associated genes

\begin{tabular}{|c|c|c|c|c|}
\hline gene name & \multicolumn{1}{|c|}{ Arp5 si } & les6 si & Ino80 si & $\begin{array}{c}\text { mutation or abnormal expression } \\
\text { in rhabdomyosarcoma }\end{array}$ \\
\hline NRAS & 0.52482259 & 0.783584319 & 1.249574324 & yes \\
\hline RALB & 0.596180532 & 0.87494941 & 0.903568535 & yes \\
\hline MAP2K1 & 0.509457747 & 0.883027783 & 1.277666369 & \\
\hline MAPK6 & 0.312978346 & 0.687366781 & 0.855019601 & yes \\
\hline FOS & 0.311179389 & 0.764731067 & 1.563109475 & \\
\hline FOSB & 0.396853222 & 0.513096564 & 1.197139445 & \\
\hline FOSL1 & 0.535727021 & 1.498812029 & 1.624624654 & \\
\hline FOSL2 & 0.541540585 & 1.026418388 & 1.227024902 & \\
\hline PIK3CA & 0.748945824 & 0.772733106 & 0.953470939 & yes \\
\hline GAB1 & 0.578477243 & 0.678945047 & 0.717119774 & yes \\
\hline GAB2 & 0.647413729 & 0.958445655 & 0.733735106 & \\
\hline GSK3B & 0.757049326 & 1.001657684 & 1.161300685 & \\
\hline PRKAA1 & 0.634251788 & 0.752985228 & 0.998777405 & \\
\hline AKT3 & 0.484577812 & 1.175766361 & 1.028708988 & \\
\hline CCND1 & 0.702267178 & 1.119207152 & 1.174654151 & yes \\
\hline ALKBH6 & 0.58572994 & 0.600586289 & 0.954363871 & yes \\
\hline MET & 0.572259543 & 1.087319262 & 0.540795433 & yes \\
\hline DAPK1 & 0.563024387 & 0.531484007 & 0.748973893 & yes \\
\hline FBXW7 & 0.689403743 & 0.913610547 & 0.565788288 & yes \\
\hline
\end{tabular}

Figure 2-figure supplement 1. Expression profiles of genes altered by Actin-related protein 5 (Arp5), Ies6, and Ino80 knockdown. (A) Scatter plot of fold changes $(\log 2)$ in the expression level of genes altered by Arp5, Ies6, and Ino80 knockdown. The dataset was filtered for genes with more than twofold increase or decrease. The Pearson's correlation coefficient (r) was calculated. (B) Venn diagrams of the number of genes whose expression level increased (left) or decreased (right) by more than 1.5-fold by Arp5, Ies6, and Ino80 knockdown. (C) Enrichment analysis of the Kyoto Encyclopedia of Genes and Genomes (KEGG) pathway from the DNA microarray data on Arp5 knockdown in RD cells. (D) Enrichment analysis of the KEGG pathway from the DNA microarray data on Ies6 knockdown in RD cells. (E) Enrichment analysis of the KEGG pathway from the DNA microarray data on Ino80 knockdown in RD cells. (F) List of cancerassociated genes whose expression level was downregulated by Arp5 knockdown in RD cells. 
codon of Arp5 were deleted by CRISPR-Cas9 genome editing, causing Arp5 deletion

122 (Figure 3A). Arp5-KO cells showed significant upregulation of many kinds of skeletal 123 muscle-related genes (Figure 3B).

124 Under culture conditions, Arp5-KO cells proliferated as well as parental RD cells

125 (doubling time of wild-type $[\mathrm{WT}] \mathrm{RD}$ cells $\left[t_{2}(\mathrm{WT})\right]=29.7 \mathrm{~h}, t_{2}(\mathrm{C} 39)=29.8 \mathrm{~h}, t_{2}(\mathrm{C} 45)$

$126=23.8 \mathrm{~h}, t_{2}(\mathrm{C} 67)=26.7 \mathrm{~h}$; Figure $\left.3 \mathrm{C}\right)$. However, when transplanted subcutaneously into

127 nude mice, they rarely formed tumor nodules differently from parental cells (Figure 3D).

128 These rare tumor nodules showed higher expression of muscle-related genes and

129 Cdkn1a, which encodes a cyclin-dependent kinase inhibitor $\mathrm{p} 21^{\mathrm{WAF} 1 / \mathrm{CIP} 1}$ controlling cell

130 cycle arrest and myogenic differentiation during muscle development and regeneration

131 (Halevy et al., 1995; Figure 3E). Thus, Arp5 deletion partially restores the impaired

132 myogenic differentiation potential of RD cells and inhibits their tumorigenesis in vivo.

134 Arp5 inhibits MyoD and MyoG activity through binding to their cysteine-rich 135 region

136 MRF transcription is regulated by positive autoregulation (Tapscott SJ, 2005). To 137 examine whether Arp5 inhibits the activity or transcription of MRF, 138 immunoprecipitation and reporter promoter analysis were performed. 139 Immunoprecipitation showed that Arp5 binds to both MyoD and MyoG but not to the 140 ubiquitous bHLH protein E47 (Figure 4A). MyoG was precipitated more efficiently 141 than MyoD with Arp5. The amino acid sequences of basic and HLH regions were 142 highly conserved between MyoD and MyoG (Figure 4-figure supplement 1), but these 143 domains were not necessary for their interaction (Figure 4B). The CR region, a part of 144 the $\mathrm{H} / \mathrm{C}$ region, was also highly conserved between them (Figure 4 -figure supplement 
A
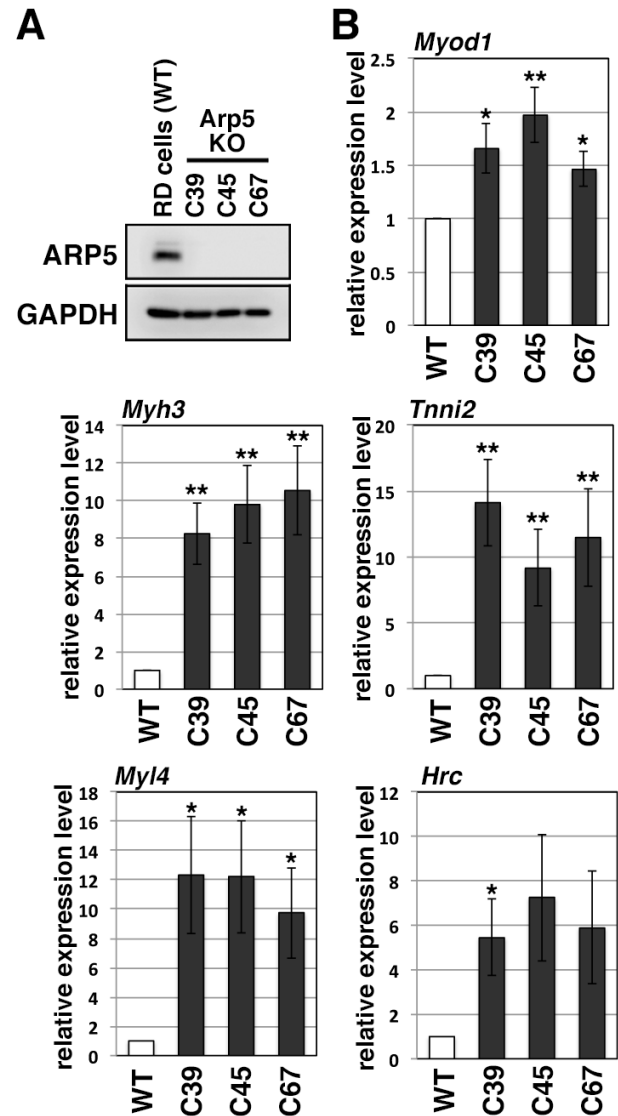

D

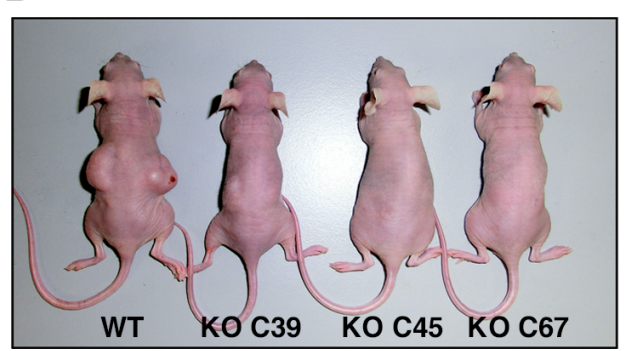

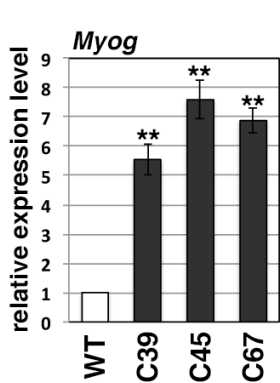
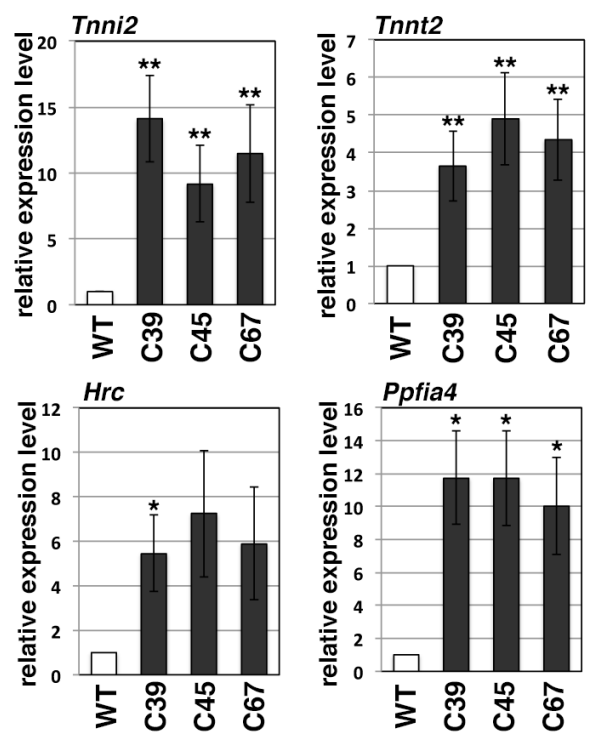
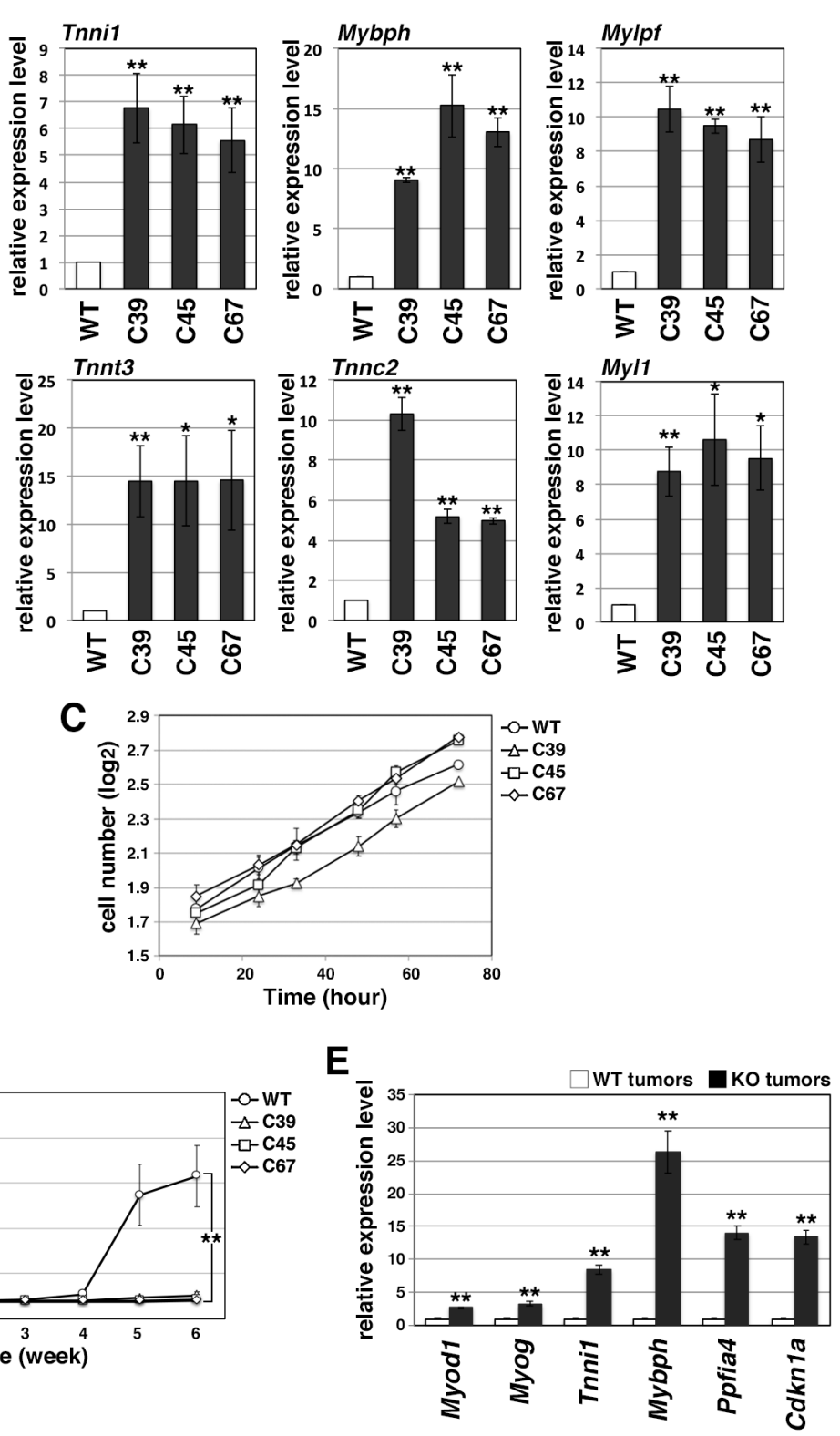

Figure 3. Actin-related protein 5-knockout (Arp5-KO) RD clones show increased expression of myogenic genes and decreased tumorigenicity. (A) Arp5 expression in three individual clones of Arp5$\mathrm{KO}$ cells (C39, C45, and C67) and their parental RD cells (wild-type [WT]). (B) Myogenic gene expression in WT and Arp5-KO cells. (C) Growth curve of WT and Arp5-KO cells. (D) Xenograft model of WT and Arp5-KO cells in nude mice (left). Tumor volumes measured every week after inoculation and statistically analyzed (right). (E) Myogenic gene expression in xenograft tumors. All statistical data are presented as the mean \pm standard error of the mean (SEM). $* P<0.05, * * P<0.01$ (Student's $t$-test). 


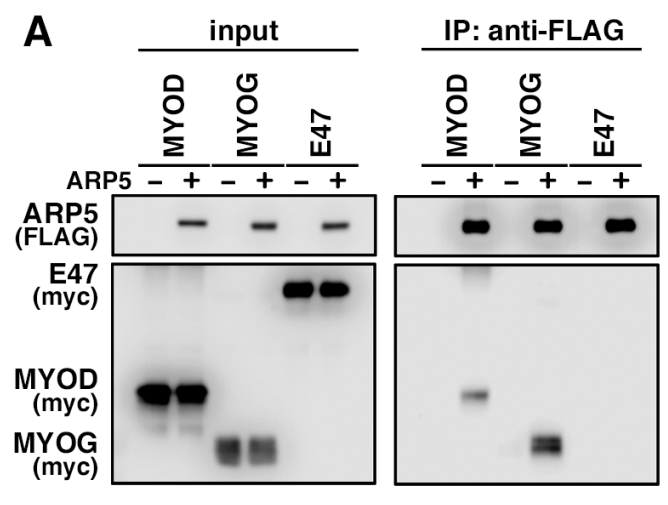

B
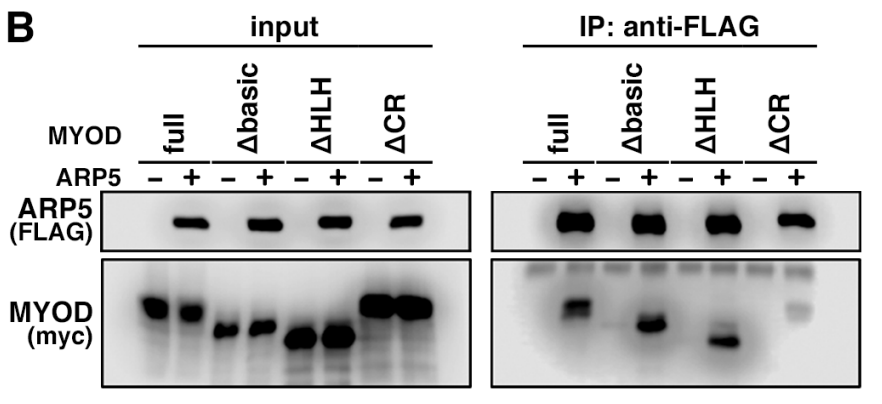

C

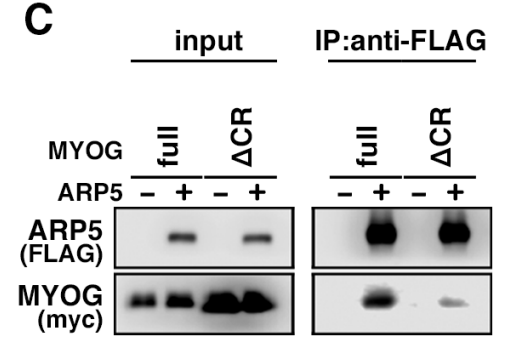

D
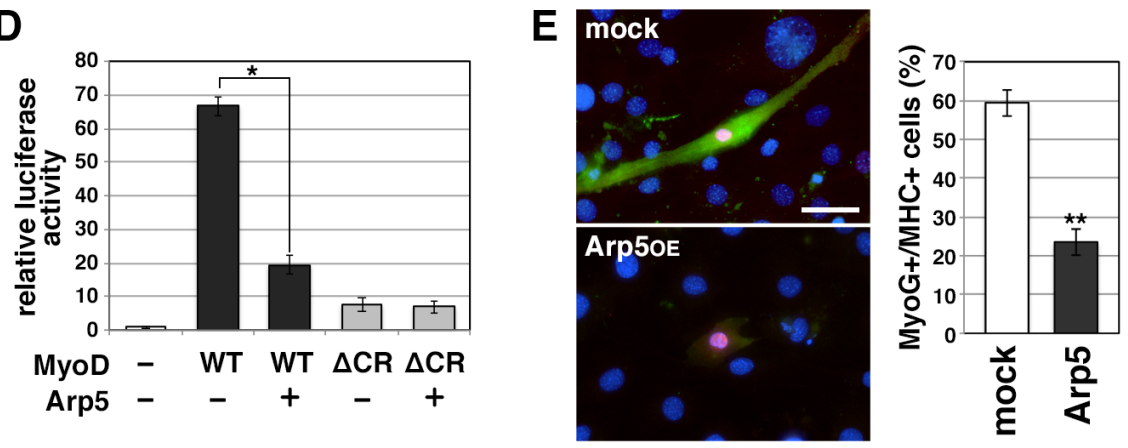

$\mathbf{F}$
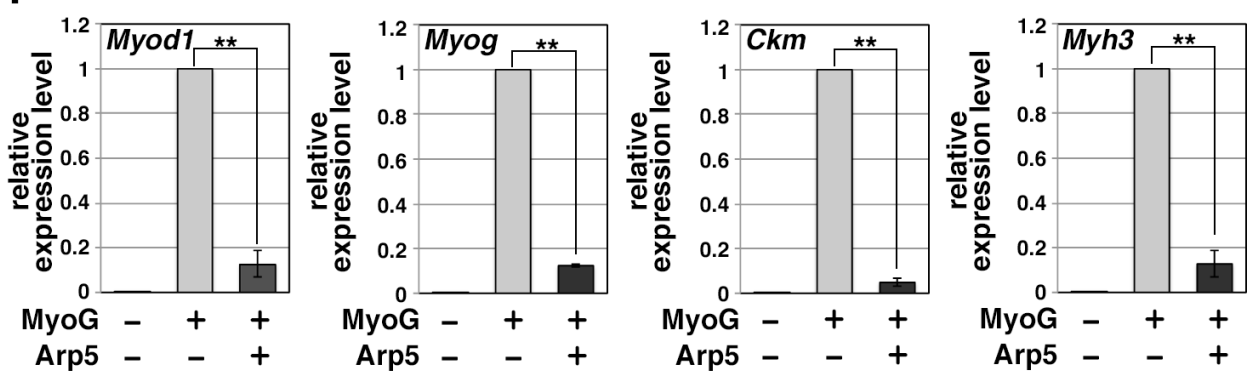

Figure 4. Actin-related protein 5 (Arp5) inhibits the activity of MyoD and MyoG through direct interaction. (A) Co-immunoprecipitation assay between Arp5 and basic helix-loop-helix (bHLH) transcription factors $\mathrm{MyoD}, \mathrm{MyoG}$, and E47. (B) Co-immunoprecipitation assay between Arp5 and truncated series of MyoD. (C) Co-immunoprecipitation assay between Arp5 and the CR-region-deleted MyoG. (D) MyoG promoter-controlled luciferase reporter assay in C2C12 cells. (E) Representative fluorescence images of 10T/2 cells transfected with MyoG and Arp5 (left). The cells were immunostained with anti-MyoG (red) and anti-myosin heavy chain (MHC, green) antibodies. Nuclei were visualized by Hoechst 33342 (blue). Scale bar $=50 \mu \mathrm{m}$. The percentage of MyoG+ MHC+ double-positive cells in MyoG+-positive cells was calculated in 786 cells and statistically analyzed (right). (F) Endogenous myogenic gene expression in 10T1/2 cells transfected with MyoG and Arp5. All statistical data are presented as the mean \pm standard error of the mean (SEM). $* \mathrm{P}<0.05, * * \mathrm{P}<0.01$ (Student's t-test). 
bioRxiv preprint doi: https://doi.ora/10.1101/2021.05.27.446008: this version posted Mav 27. 2021. The copvriaht holder for this preprint (which was not certified by peer review) is the author/funder, who has granted bioRxiv a license to display the preprint in perpetuity. It is made available under aCC-BY 4.0 International license.

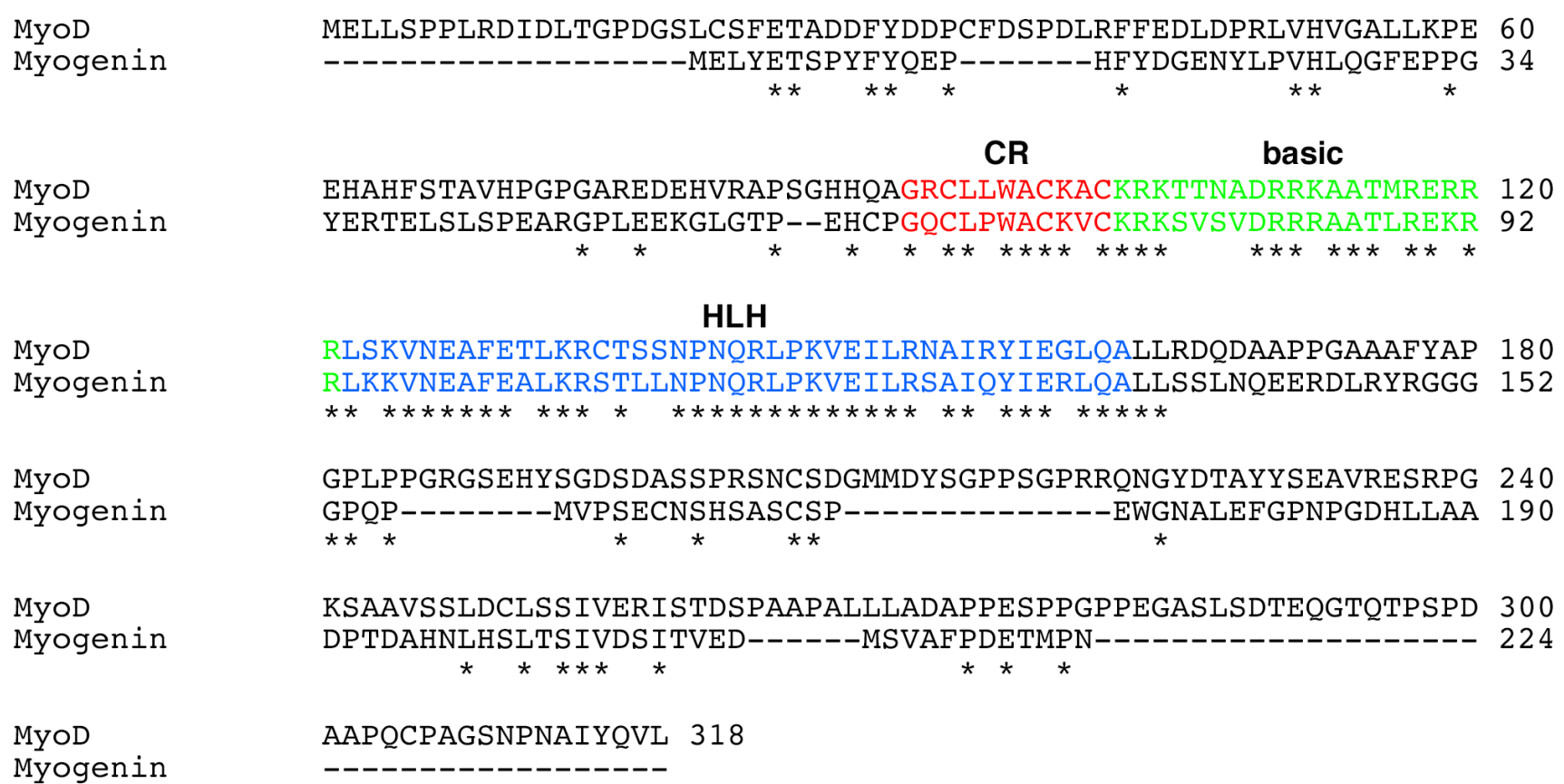

Figure 4-figure supplement 1. Sequence alignment between human MyoD and MyoG proteins. The CR (red), basic (green), and helix-loop-helix (HLH) regions are highlighted. Asterisks indicate conserved amino acid residues between them. 
145 1), and CR region deletion mostly abolished the Arp5-binding ability of both MyoD and

146 MyoG (Figure 4B,C). MyoG promoter-controlled luciferase reporter assay 147 demonstrated that MyoD strongly enhances MyoG promoter activity, while Arp5 148 significantly inhibits it (Figure 4D). MyoD $\triangle \mathrm{CR}$, in which the CR region was deleted, 149 also increased MyoG promoter activity but to a lesser extent, and this activation was completely unaffected by Arp5 (Figure 4D), indicating that the direct interaction with MyoD via the CR region is necessary for Arp5 to inhibit MyoD activity.

Ectopic MyoG expression differentiated 10T1/2 cells into MHC-positive myogenic cells with induction of endogenous myogenic marker genes such as Myodl, MyoG, Ckm, and Myh3 (Figure 4E,F). Co-expression of Arp5 with MyoG, however, significantly decreased the frequency of MHC-positive cells and significantly inhibited the induction of myogenic genes (Figure 4E,F). Thus, Arp5 inhibits MyoD/MyoG activity through direct interaction via their $\mathrm{CR}$ region.

Arp5 competes with Pbx1-Meis1 for binding to the cysteine-rich region of

\section{MyoD/MyoG}

161 The $\mathrm{H} / \mathrm{C}$ region of $\mathrm{MyoD}$ is an essential region for its chromatin remodeling activity 162 and effective induction of target genes (Gerber et al., 1997). Pbx1 and Meis1 homeobox 163 proteins are promising candidates as mediators between MyoD and chromatin 164 remodelers because MyoD binds to $\mathrm{Pbx} 1$ and Meis 1 via the $\mathrm{H} / \mathrm{C}$ region (Knoepfler et al., 165 1999). MyoD and the Pbx1-Meis1 heterodimer interacted in the absence of the 166 intermediary DNA; furthermore, this interaction was interrupted by Arp5 (Figure 5A).

167 The MyoG locus has been most analyzed for MyoD-mediated chromatin remodeling. 168 The proximal promoter region of $M y o G$ reportedly contains two flanking sequences, 
A

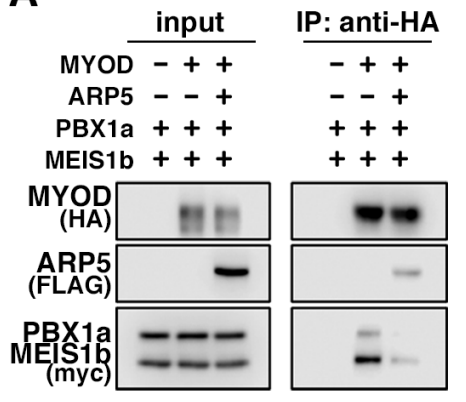

B

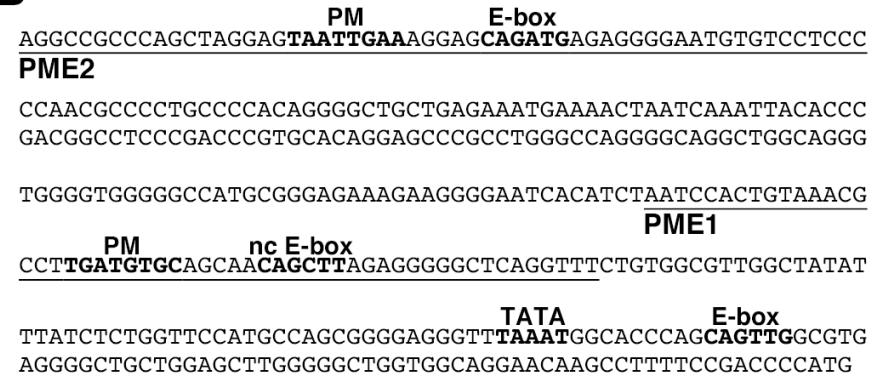

C

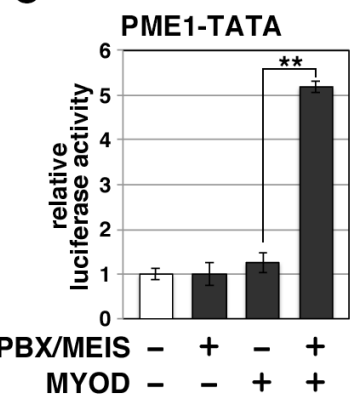

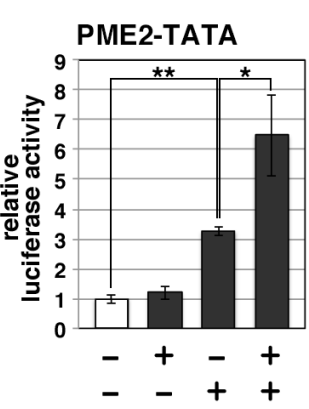

D

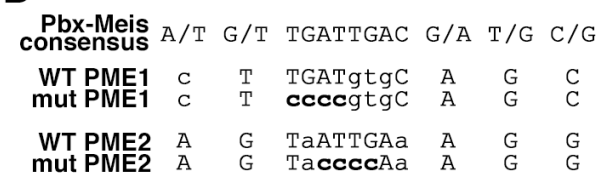

\begin{tabular}{|c|c|c|c|c|}
\hline & \multicolumn{2}{|c|}{ input } & \multicolumn{2}{|c|}{ pull down } \\
\hline & PME1 & PME2 & PME1 & PME2 \\
\hline & 々芌 & 々节 & 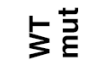 & 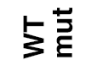 \\
\hline $\begin{array}{l}\text { PBX1a } \\
\text { MEIS1b }\end{array}$ & $=2$ & 20 & $\bar{E}$ & $\vec{a}$ \\
\hline
\end{tabular}

E

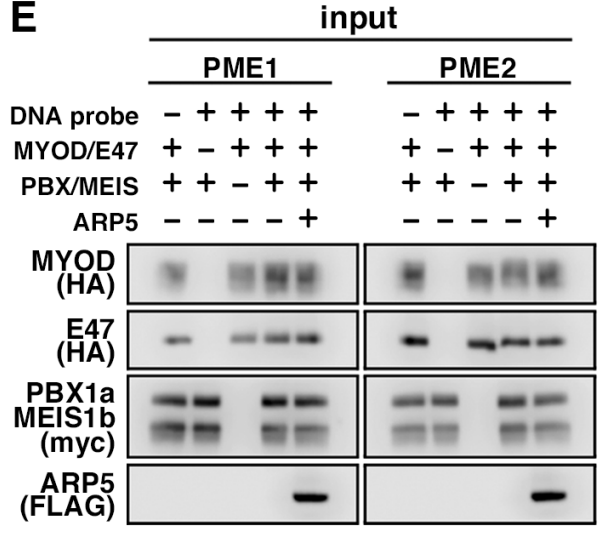

pull down

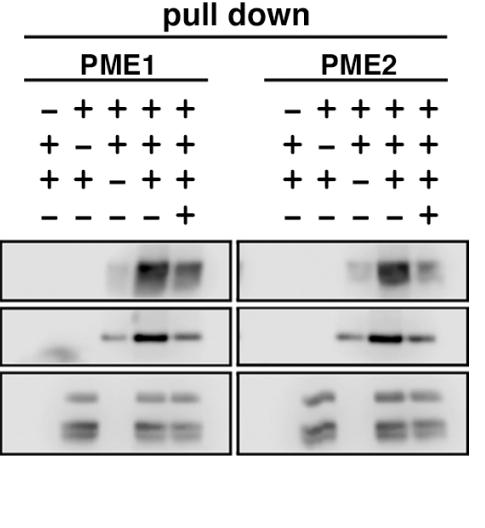

Figure 5. Actin-related protein 5 (Arp5) disturbs the interaction between MyoD and the Pbx1-Meis1

heterodimer. (A) Co-immunoprecipitation assay between MyoD and Pbx1a-Meis1b. Co-incubation with Arp5 protein (lanes 3 and 6) diminished their interaction. (B) Sequence of the proximal promoter region of human MYOG. The core sequences of the indicated cis-regulatory elements are highlighted in bold. Pbx1Meis1 heterodimer-binding motif/noncanonical E-box (PM/ncE)-containing regions (PME1 and PME2) are underlined. (C) PME1/2-TATA-controlled luciferase reporter assay in C2C12 cells. (D) Pull-down assay of PME1/2 DNA probes with Pbx1a-Meis 1b protein. The consensus sequence of the PM motif is presented. The mutated nucleotides in the mut PME1/2 probes are highlighted in bold. (E) Pull-down assay of PME1/2 DNA probes with MyoD, E47, Pbx1a-Meis1b, and Arp5 proteins. 
Pbx1-Meis1 heterodimer-binding motif (PM) and noncanonical E-box (ncE) (Berkes et al., 2004; Figure 5B). When this regulatory region $(\mathrm{PM} / \mathrm{ncE}$-containing region 1

171 [PME1]) was fused to the TATA minimal promoter, the PME1-TATA construct was 172 activated by the combination of $\mathrm{Pbx} 1$, Meis1, and MyoD (Figure 5C, left). Upstream of 173 PME1, a novel predicted regulatory region containing PM and E-box motifs (PME2) was identified (Figure 5B). A pull-down assay using DNA-probe-conjugated beads of the PMEs demonstrated that the Pbx1-Meis1 heterodimer recognizes the PM motif of both PME1 and PME2 and that this interaction completely disappears by disruption of the PM motif via mutagenesis (Figure 5D). The PME2-TATA construct was also synergically activated by MyoD and the Pbx1-Meis1 heterodimer (Figure 5C, right). Thus, both PME1 and PME2 are functional cis-regulatory elements for MyoD and the Pbx1-Meis1 heterodimer.

The DNA-protein pull-down assay also demonstrated that the MyoD-E47

182 heterodimer weakly binds to PME1 and PME2 DNA probes, which is significantly 183 augmented by co-incubation with the Pbx1-Meis1 heterodimer (Figure 5E). The Pbx1Meis1 heterodimer was constantly associated with the PMEs regardless of whether MyoD-E47 was present. Arp5 interrupted the augmented interaction of MyoD-E47 with the PMEs but did not affect the interaction of the Pbx1-Meis1 heterodimer with the PMEs (Figure 5E).

188 We also identified the predicted PME element in the proximal promoter region of Myf6, which contains Pbx- and Meis-binding motifs separated by six nucleotides (acTGATgctccaTGACag) close to noncanonical E-boxes (Figure 6A). Jacobs et al. (1999) reported that this type of gapped PM site is also functional for the Pbx1192 Meis1-binding site, and we observed significant interaction between the Pbx1-Meis1 
A

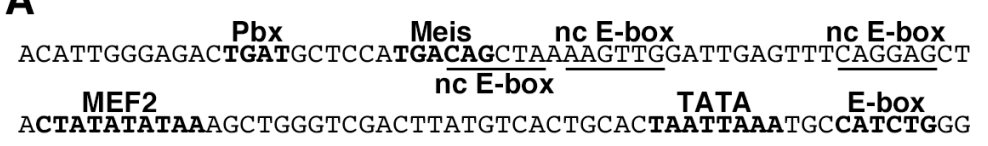
TGGTTCCTCTGGGTTTTTTGAGTCCATCACCCAGTTCAGATCGAGTCAGAGGCCAAG GAGGAGAACATG

B

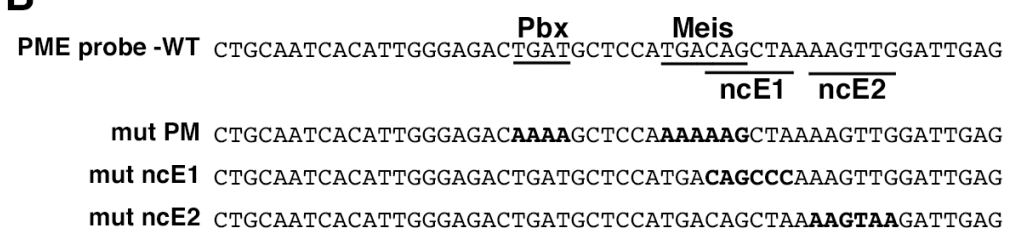

C

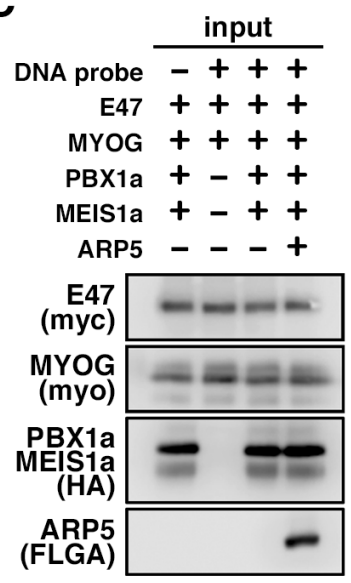

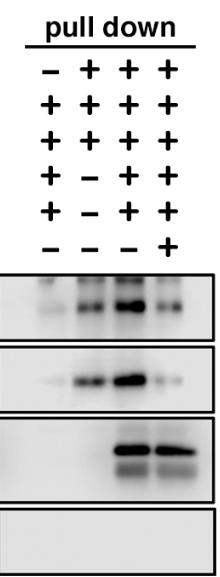

Figure 6. MyoG and the $\mathrm{Pbx1}-\mathrm{Meis} 1$ heterodimer recognize the proximal promoter region of human myogenic regulatory factor 6 (MRF6). (A) Sequence of the proximal promoter region of human MRF6. The core sequences of the indicated cis-regulatory elements are highlighted in bold. The core sequences of putative noncanonical E-box motif (nc E-box) are underlined. (B) Pull-down assay of Mrf6 Pbx1-Meis1 heterodimer-binding motif/noncanonical E-box (PM/ncE)-containing region (PME) probes with MyoG, E47, and Pbx1a-Meis1b proteins. The mutated nucleotides in the mut PME probes (mut PM, mut ncE1, and mut ncE2) are highlighted in bold (top). The Pbx1-Meis1 heterodimer recognized the gapped PbxMeis-binding motif, while MyoG-E47 bound to the ncE1 site with the Pbx-Meis complex (bottom). (C) Pull-down assay of Mrf6 PME probes with MyoG, E47, Pbx1a-Meis1b, and Arp5 proteins. 
193 heterodimer and Myf6's PM motif (Figure 6B). Similar to PMEs in the MyoG promoter,

194 MyoG bound to Myf6's PME synergically with the Pbx1-Meis1 heterodimer, while

195 Arp5 interrupted this binding (Figure 6C). These findings show that Arp5 attenuates

196 MyoD/MyoG recruitment to PME-containing myogenic enhancer regions by disturbing

197 the interaction between MyoD/MyoG and the Pbx1-Meis1 heterodimer.

\section{Arp5 prevents Brg1-SWI/SNF complex recruitment to MyoD/MyoG target loci}

During MyoD-mediated chromatin remodeling, the Pbx1-Meis1 heterodimer is believed to be involved in the recruitment of Brg1-based SWI/SNF chromatin remodeling complex to MyoD target loci as a pioneering factor (de la Serna et al., 2001). Serna et al. (2005) reported that the induction of approximately one-third of MyoD target genes depends on the Brg1-SWI/SNF complex. Therefore, we investigated the change in MyoD target gene expression by Arp5-si in terms of Brg1 dependency. Arp5-si upregulated Brg1-dependent genes to a larger extent compared to Brg1-independent genes (1.77-fold vs. 1.38-fold, $p=0.02$; Figure 7A). This Brg1 dependency was seen more clearly by comparing the effect of Arp5-si versus Ies6-si and Ino80-si: Arp5-si more effectively increased Brg1-dependent gene expression compared with Ies6-si and Ino80-si, whereas Brg1-independent gene alteration was comparable between them (Figure 7A). Thus, Arp5, but not Ies6 and Ino80, affects the expression of

212 MyoD target genes in a Brg1-dependent manner.

213 To determine the role of Arp5 in regulating Brg1 recruitment to MyoD target loci, we 214 performed chromatin immunoprecipitation (ChIP) assay using Arp5-KO RD cells. 215 MyoD, MyoG, Pbx, and Brg1 were recruited to the proximal promoter region of Myog. 216 MyoD, MyoG, and Brg1 significantly accumulated in Arp5-KO cells compared with 
A
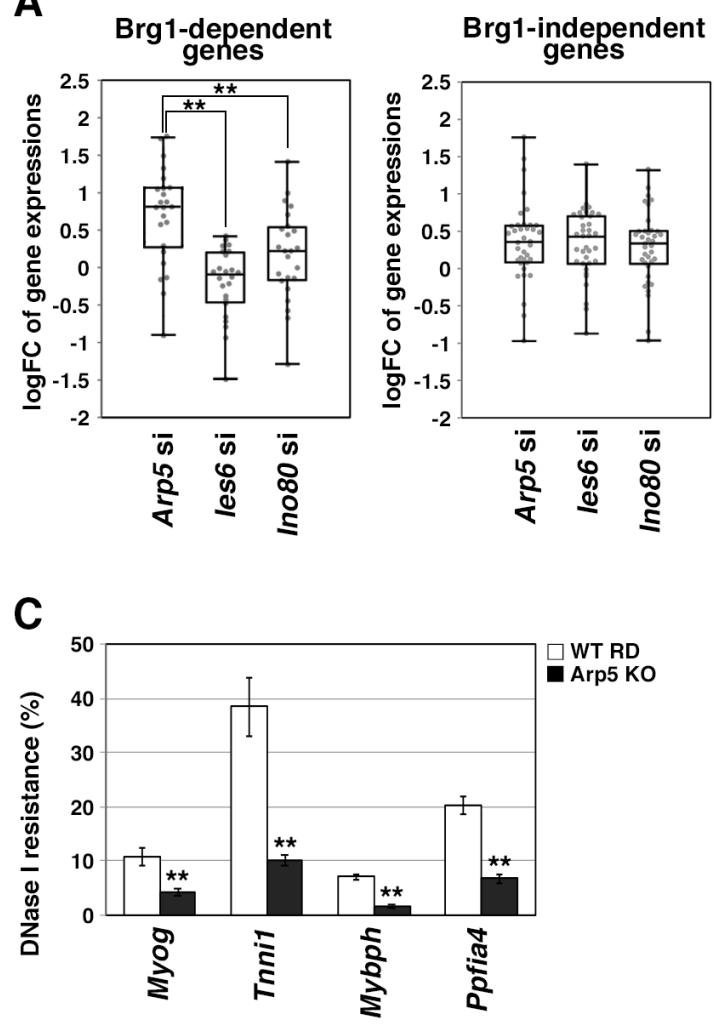

B
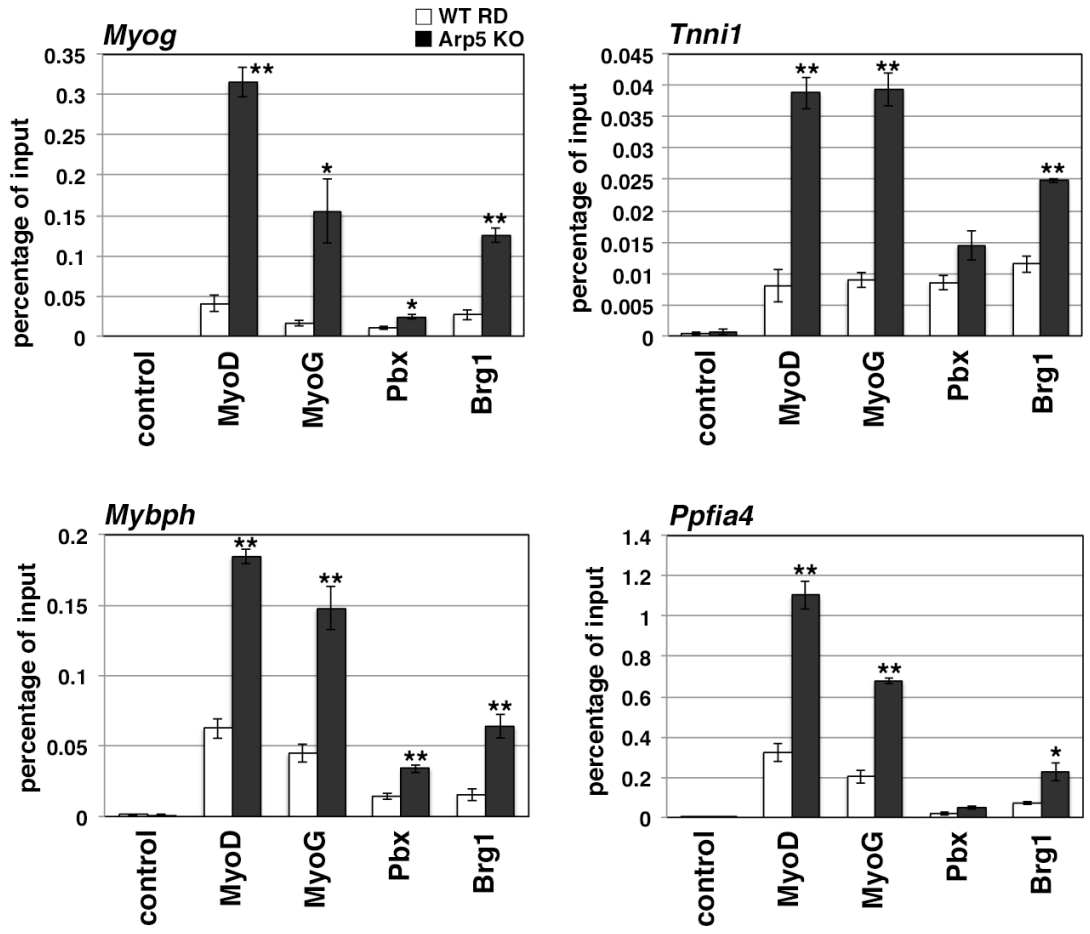

Figure 7. Actin-related protein 5 (Arp5) inhibits the recruitment of MyoD, MyoG, and Brg1-based switch/sucrose nonfermentable (SWI/SNF) to the enhancer region of myogenic genes. (A) Box-andwhisker plot of fold changes $(\log 2)$ in the expression level of Brg1-dependent and Brg1-independent myogenic genes by Arp5, Ies6, and Ino80 knockdown. (B) Chromatin immunoprecipitation (ChIP) analysis using antibodies against MyoD, MyoG, Pbx, and Brg1 in wild-type (WT) and Arp5-knockout (KO) cells. Enrichment efficiency of DNA fragments of MyoG, Tnni1, Mybph, and Ppfia4 enhancer loci was quantified by real-time polymerase chain reaction (PCR). (C) DNase I sensitivity assay of the enhancer loci in WT and Arp5-KO RD cells. All statistical data are presented as the mean \pm standard error of the mean (SEM). $* \mathrm{P}<0.05, * * \mathrm{P}<0.01$ (Student's t-test). 
217 parental RD cells (Figure 7B). Arp5 KO increased Pbx1 recruitment to a lesser extent.

218 ChIP assay against the enhancer regions of Brg1-dependent myogenic genes, Tnnil,

219 Mybph, and ppfia4, using public ChIP-Seq and DNase I hypersensitive site (DHS)-Seq

220 databases identified Pbx1- and MyoD-binding regions in their promoter and intronic

221 regions; these regions were DNase I hypersensitive and positive for H3K27Ac, which

222 are markers for the identification of active enhancer regions (Figure 7-figure

223 supplement 1). Pbx-Meis-binding motifs actually exist close to canonical and

224 noncanonical E-box motifs in the focused areas (Figure 7-figure supplement 1). ChIP

225 data showed that all the proteins of interest were recruited to the predicted enhancer

226 regions and that Arp5 KO significantly augmented MyoD, MyoG, and Brg1

227 accumulation in these regions (Figure 7B).

228 Finally, we investigated the involvement of Arp5 in chromatin structure alteration of

229 the MyoD/MyoG target loci. DNase I accessibility to the above-mentioned regions was

230 compared between Arp5-KO and parental RD cells (Figure. 7C). The accessibility of all

231 the target regions was significantly higher in Arp5-KO RD cells. The findings illustrate

232 that Arp5 binds to MyoD and MyoG competitively with the Pbx1-Meis1 heterodimer

233 and prevents the recruitment of the Brg1-SWI/SNF complex to their target loci,

234 resulting in chromatin accessibility attenuation and, therefore, transcriptional

235 suppression of myogenic genes.

\section{Discussion}

238 In this study, we demonstrated a novel role of Arp5 in skeletal muscle differentiation.

239 The $\mathrm{H} / \mathrm{C}$ region of MyoD is critical for its chromatin remodeling activity. MyoD

240 interacts with some epigenetic regulators, such as SWI/SNF, histone deacetylase 
241 (HDAC), p300 histone acetyltransferase (HAT), and p300/CBP-associated factor

242 (PCAF) (Yuan et al., 1996; Puri et al., 1997; Lu et al., 2000; Serna et al., 2001), but how

243 the $\mathrm{H} / \mathrm{C}$ region contributes to epigenetic regulation is unclear. The $\mathrm{Pbx} 1-\mathrm{Meis} 1$

244 heterodimer is so far the only identified partner of MyoD-binding directly to this region.

245 Here we reported Arp5 as another binding partner, which competes with the Pbx1-

246 Meis1 heterodimer for binding to the $\mathrm{H} / \mathrm{C}$ region. The Pbx1-Meis1 heterodimer is

247 believed to recognize the PM motif in the enhancer region of myogenic genes and acts

248 as a pioneering factor by marking this locus for the recruitment of MyoD and its

249 co-factors, such as epigenetic regulators (Cho et al., 2015). Our findings clearly show

250 that the Pbx1-Meis1 heterodimer directly binds to the PM motifs in the promoter region

251 of $M y o G$ and Myf6 and augments the MyoD and MyoG binding to the canonical and reveal $\mathrm{Pbx} 1$ recruitment to the enhancer regions of some myogenic genes with MyoD.

254 Arp5 inhibits the recruitment of MyoD and MyoG to Pbx1-Meis1-marked loci and, consequently, attenuates the recruitment of chromatin remodelers, such as Brg1SWI/SNF. Therefore, low Arp5 expression in skeletal muscle tissues contributes to an increase in the chromatin accessibility of MyoD/MyoG target loci and the maintenance of high transcriptional activity of myogenic genes.

Arp5 is a well-known subunit of INO80 and plays an essential role in its ATPase activity and nucleosome sliding (Yao et al., 2015). In HeLa cells knocked down for each subunit of INO80, such as Ino80, Arp8, Ies2, and Ies6, the expression of many genes was altered, and these genes were enriched in several functional pathways such as the

263 p53 signaling pathway, cell cycle, focal adhesion, and extracellular matrix-receptor 264 interaction (Cao et al., 2015). These profiling data are in good agreement with our 

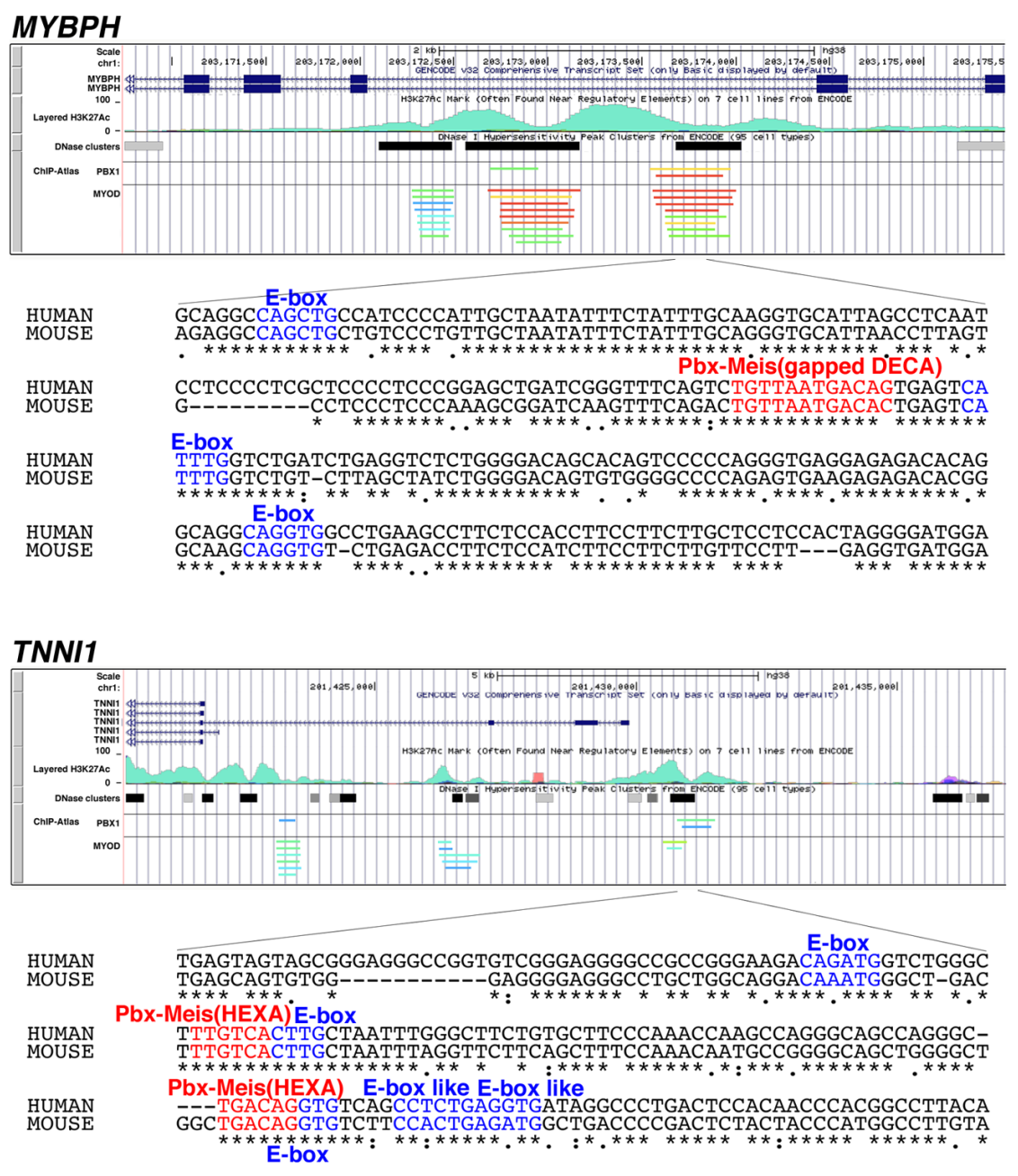

PPFIA4
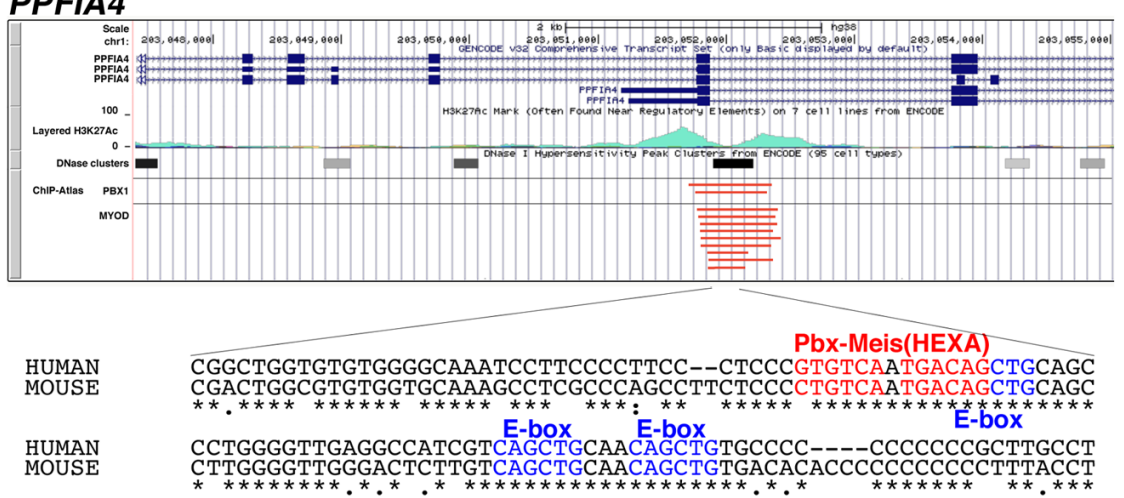

Figure 7-figure supplement 1. Putative enhancer regions recognized by Pbx1 and MyoD/MyoG in human MYBPH, TNNI1, and PPFIA4. Data on the enrichment of H3K27Ac histone markers and DNase I hypersensitivity clusters were acquired from the Encyclopedia of DNA Elements (ENCODE) public database, version 3 (https://www.encodeproject.org). Data on the chromatin immunoprecipitation (ChIP) sequence were acquired from the ChIP-Atlas public database (https://chip-atlas.org). Nucleotide sequences of putative enhancer regions are presented with highlighted $\mathrm{Pbx}$-Meis-binding motif (red) and E-box motif (blue). Decameric (DECA, TGATTGACAG) and hexameric (HEXA, TGACAG) motifs are reported as a consensus sequence of the $\mathrm{Pbx}-$ Meis-binding site. 
results using Ino80-si RD cells (Figure 2-figure supplement 1A-E). In osteogenic

266 differentiation of mesenchymal stem cells, INO80 interacts with the WD repeat domain

2675 protein and regulates osteogenic marker expression (Zhou et al., 2016). When 11

268 kinds of INO80 subunits are knocked down in mesenchymal stem cells, all the

269 knockdown cells show a reduction in calcium deposition. Thus, each subunit seems

270 indispensable for the function of INO80. In contrast, we observed many muscle-related

271 genes to be upregulated only in Arp5-si cells but not in Ies6- and Ino80-si cells. Besides,

272 Arp5 alone interrupted MyoD/MyoG-Pbx1-Meis1 complex formation, thereby

273 inhibiting their activities. These results suggest that Arp5 regulates the activities of

274 MyoD and MyoG independently of INO80. We previously demonstrated the

275 INO80-independent role of Arp5 in regulating the phenotypic plasticity of SMCs

276 through direct interaction with myocardin (Morita et al., 2014). Yao et al. (2016)

277 reported that the total abundance of Arp5 in cells is approximately eightfold of that as a

278 component of INO80. Thus, Arp5 seems to have multiple functions besides being a

279 subunit of INO80.

280 RMS cells are useful for analyzing the antimyogenic function of Arp5 because they

281 highly express Arp5 and MRFs simultaneously. MyoD and MyoG are potent markers of

282 RMS and can induce terminal myogenic differentiation, while their activities are

283 post-transcriptionally dysregulated in RMS (Keller and Guttridge, 2013). Our results

284 provide insight into the post-transcriptional regulation of MyoD and MyoG: abundant

285 Arp5 in RMS induces MyoD and MyoG dysfunction via direct interaction. Arp5

286 deletion in $\mathrm{RD}$ cells leads to a loss of their tumorigenicity in nude mice due to the

287 enhancement of myogenic differentiation. Arp5 is also identified as a T-cell acute

288 lymphocytic leukemia and sarcoma antigen (Lee et al., 2003), although its contribution 
to carcinogenesis and sarcomagenesis is unclear. In Arp5-si RD cells, the expression of several cancer-associated genes decreased, including those reported to be mutated and abnormally expressed in RMS (Figure 2-figure supplement 1F). Survival data from

292 The Cancer Genome Atlas reveal that high Arp5 expression is unfavorable for the prognosis of liver and renal carcinoma (data not shown). Thus, Arp5 likely has oncogenic properties, in addition to its inhibitory role in myogenesis. skeletal muscle. In contrast, RMS shows increased Arp5 expression with dysregulation of myogenic differentiation compared with tumor-adjacent skeletal muscles. Haldar et al. (2007) reported a synovial sarcoma mouse model in which the ectopic expression of a chimeric SYT-SSX fusion gene was driven from the Myf5 promoter. In the tumors, Arp5 expression was approximately fivefold upregulated, while several myogenic markers were downregulated. Thus, Arp5 expression seems to be regulated according to the differentiation stage of skeletal muscle lineage cells. Alternative splicing coupled to nonsense-mediated messenger RNA (mRNA) decay (AS-NMD) is important for

304 keeping the expression of Arp5 low in differentiated SMCs (Morita et al., 2014). AS-NMD contributes to post-transcriptional fine-tuning of broad gene expression (Nasif et al., 2018); furthermore, depletion of the splicing factor U2AF35 increased Arp5 mRNA levels in Hek293 cells (Kralovicova et al., 2015). Tissue-specific alternative splicing is most frequently observed in skeletal muscle, and these splicing events are critical for proper skeletal muscle development and function (Nakka et al., 2018). These facts raise the possibility that AS-NMD contributes to the regulation of Arp5 expression

311 in skeletal muscle and RMS.

312 This study reported a novel function of Arp5 in myogenic differentiation and 
313 tumorigenesis. Arp5 is a novel modulator of MRFs in skeletal muscle differentiation.

314 Our data also cultivated a better understanding of chromatin remodeling events

315 mediated by MRFs and Pbx-Meis in myogenic gene expression. The major limitations

316 of this study are the lack of data on the change in Arp5 expression and its relevance to

317 MRF activation during skeletal muscle development in vivo. Although in vivo

318 experiments were performed using the AAV6 vector, further studies are needed to fully

319 elucidate the mechanism and significance of low Arp5 expression in muscle tissues. It

320 will be also interesting to investigate whether transcriptional and post-transcriptional

321 regulation of Arp5 contributes to physiological and pathological skeletal muscle

322 dysfunction.

Materials and Methods

\section{Cell cultures, treatment, and transfections}

326 Human RMS RD cells (supplied by the Japanese Collection of Research Bioresources

327 cell bank), human skeletal myoblasts (Thermo Fisher Scientific), and mouse C3H muscle myoblasts (C2C12 cells; ATCC) were cultured in Dulbecco's Modified Eagle's Medium (DMEM) supplemented with 20\% FCS. Mouse primary fibroblasts were isolated from the hind limbs of 3-week-old C57BL/6j mice as follows: The extracted

331 hind limb muscle tissues were minced and incubated in a digestion solution (260 U type

332 I collagenase, 3000 PU dispase II, and $10 \mathrm{mM} \mathrm{CaCl}_{2}$ in $1 \mathrm{~mL}$ of Hanks' Balanced Salt solution [HBSS]) for $60 \mathrm{~min}$ at $37^{\circ} \mathrm{C}$. The dispersed cells were washed twice with HBSS and plated on a type I collagen-coated culture dish with DMEM. After 30 min of incubation, the culture medium was removed, and the attached cells were cultured with 
336 DMEM supplemented with 20\% FCS. The differentiated myoblasts were incubated in

337 differentiation medium (DMEM supplemented with 2\% house serum) for 1-3 days.

338 For myogenic transdifferentiation of the mouse embryo cell line, 10T1/2 cells

339 (ATCC) were treated with $3 \mu \mathrm{M}$ 5-azacitidine for $24 \mathrm{~h}$ and then cultured in DMEM 340 supplemented with $10 \%$ FCS for 3-7 days.

341 To establish Arp5-KO cell lines, RD cells were transfected with the all-in-one

342 Cas9/gRNA plasmid pSpCas9 BB-2A-GFP (PX458; Addgene; gRNA target sequence,

343 ccgttccgegacgeccgtgccgc). One day after transfection, green fluorescent protein

344 (GFP)-positive cells were sorted and individually cultured. Gene KO in the isolated 345 clones was validated by DNA sequencing and Western blotting.

346 In knockdown experiments, cells were transfected with predesigned siRNAs using

347 Lipofectamine RNAiMAX (Thermo Fisher Scientific). The siRNA sequences are listed 348 in Table 1. In overexpression experiments, cells were transfected with pCAGGS 349 expression vectors using Lipofectamine 3000 (Thermo Fisher Scientific). The coding 350 sequences of human ARP5, MYOD1, MYOG, E47, Pbxla, and MEIS1b were inserted 351 into vectors with FLAG-, HA-, and Myc-tag sequences. For the intramuscular 352 expression of exogenous Arp5, the adeno-associated virus pseudotype 6 (AAV6) 353 expression vector encoding ARP5 was constructed using AAVpro Helper Free System 354 (AAV6) (TAKARA BIO). Finally, titration of AAV6 particles was performed using the 355 AAVpro titration kit (TAKARA BIO).

Animal studies

358 All animal experiments were conducted in accordance with the guidelines for animal 359 experiments specified by the Wakayama Medical University, Japan, and Osaka 
bioRxiv preprint doi: https://doi.org/10.1101/2021.05.27.446008; this version posted May 27, 2021. The copyright holder for this preprint (which was not certified by peer review) is the author/funder, who has granted bioRxiv a license to display the preprint in perpetuity. It is made available under aCC-BY 4.0 International license.

Table 1. List of PCR primer and siRNA sequences used in this study

real time RT-PCR

\begin{tabular}{|c|c|c|c|}
\hline gene name & species & forward primer sequence $\left(5^{\prime} \rightarrow 3^{\prime}\right)$ & anti-sense primer sequence $\left(5^{\prime} \rightarrow 3^{\prime}\right)$ \\
\hline 18srRNA & mouse/human & gtaacccgttgaaccccatt & cccatccaatcggtagtagcg \\
\hline 28 srRNA & mouse/human & gcgacctcagatcagacgtg & gggtcttccgtacgccacat \\
\hline rpl13a & mouse/human & tgccgaagatggcggagg & cacagcgtacgaccaccacct \\
\hline actr5 & mouse/human & agcaagccagagacccctga & agccttgggtacctgtccag \\
\hline myod1 & mouse & ggatggtgtccctggttctc & cctctggaagaacggcttcg \\
\hline myog & mouse & ggcaatggcactggagttcg & gcacacccagcctgacagac \\
\hline myf6 & mouse & ccagtggccaagtgttcg & cgctgaagactgctggagg \\
\hline myh1 & mouse & gtcaacaag ctgcgggtgaa & ggtcacttcctg cacttggatc \\
\hline myh2 & mouse & ggetgtcccgatg ctgtg & cacacaggcgcatgaccaa \\
\hline myh3 & mouse & ctccagcagcgtagagagcg & ctagttgacgactcag ctcaccc \\
\hline myh4 & mouse & gtgaagagccgagaggttcacac & ctcctgtcacctctcaacagaaagatg \\
\hline acta 1 & mouse & gcactcgcgtctgcgttc & cctgcaaccacagcacgatt \\
\hline tnni1 & mouse & cgacctcccagtagaggttggc & gaaagataggtgagtggggctgg \\
\hline myd1 & human & cccgegctccaactgctc & cggtggagatgcgctccac \\
\hline myog & human & ggcagtggcactggagttcag & gtgatgctgtccacgatgga \\
\hline myf6 & human & gatttcctgcgcacctgca & cgaaggctactcgaggctgacg \\
\hline cdh15 & human & ctggacatcgecgacttcatc & gagggctgtgtcgtaaggcg \\
\hline mybph & human & aggcatctgtggactgccg & cctcatcacagcctcctccc \\
\hline mylpf & human & gaggatgtgatcaccggagcc & tggtcagcagctcctccagg \\
\hline tnni1 & human & ccatgtctgg catggaaggc & aggagctcagagcgcagcac \\
\hline tnni2 & human & ggacacagagaaggagcggg & cgagtggcctaggactcggactc \\
\hline tnnt2 & human & gcaggagaagttcaagcagcaga & ccggtgactttagcettcccg \\
\hline tnnt3 & human & agaccctgcaccagctggag & cggctcctgagcgtggtgat \\
\hline tnnc2 & human & gacggcgacaagaacaacga & ggtagaggcgactgtccactcc \\
\hline myh3 & human & cgagacttcacctccagcagg & ctgtcctgctccagaagggc \\
\hline myl1 & human & acatcatgtctatctgaatggagctctc & ctggagagtttgtcatgggtgtg \\
\hline myl4 & human & catcatgtcagggtgaagcagagtc & catctcagctcacccagccg \\
\hline hrc & human & cggtctgcgctccaggaag & ccagcatgtctgccagggc \\
\hline atp2a1 & human & tgcaagtcsttgggctcga & ctgtgacacgggctcagagatg \\
\hline ppfia4 & human & gccaaagaagatcatgcctgaag & gccatggctagtcccggaag \\
\hline cdkn1a & human & gctctgctgcaggggacag & gaaatctgtcatgctggtctgcc \\
\hline
\end{tabular}

ChIP assay \& DNase I sensitivity assay

\begin{tabular}{|c|c|c|c|}
\hline gene name & species & forward primer sequence $\left(5^{\prime} \rightarrow 3^{\prime}\right)$ & anti-sense primer sequence $\left(5^{\prime} \rightarrow 3^{\prime}\right)$ \\
\hline myog & human & ggccatgcgggagaaagaag & cgctggcatggaaccagag \\
\hline tnni1 & human & gggaagacagatggtctgggc & ggcctatcacctcagaggctg \\
\hline mybph & human & cggagctgatcgggttcag & gcttcaggccacctgcct \\
\hline ppfia4 & human & gcgtgcctggctccagttac & cagggctgcagctgtcattg \\
\hline
\end{tabular}

knockdown assay

\begin{tabular}{|c|c|c|}
\hline gene name & species & target sequence $\left(\mathbf{5}^{\prime} \rightarrow \mathbf{3}^{\prime}\right)$ \\
\hline control & - & MISSION siRNA Universal Negative control (Sigma) \\
\hline arp5 & mouse & acagatggaccagtttcac \\
\hline arp5 & human & cctggcatgaaagccagaa \\
\hline ies6 & human & actgcggttcagcaccatt \\
\hline ino80 & human & agcagctgccctacgggca \\
\hline
\end{tabular}


360 University School of Medicine, Japan.

361 For Arp5 overexpression in mouse skeletal muscle tissues, we injected $1 \times 10^{9} \mathrm{gv} / \mu \mathrm{L}$ 362 of control-AAV6 (empty vector) or Arp5-AAV6 vector injected into the hind limbs of 363 5-day-old C57BL/6j mice. Five weeks after injection, the hind limb muscles were extracted, fixed in $10 \%$ formalin, embedded in paraffin, and then cut into 5 - $\mu$ m-thick sections. The sections were stained with hematoxylin and eosin and observed. basement membrane matrix (FUJIFILM Wako Pure Chemical Corporation) diluted to 1:1 with phosphate-buffered saline (PBS), and $200 \mu \mathrm{L}$ of the suspension was subcutaneously inoculated into both sides of the flank of 3-week-old nude mice. The tumor size was measured every week using a pair of calipers, and the tumor volume was estimated as volume $=1 / 2\left(\right.$ length $\times$ width $\left.^{2}\right)$. After 6 weeks of inoculation, the mice were sacrificed and xenograft tumors were extracted to obtain total RNA.

\section{Immunocytochemistry}

375 Cells were cultured on coverslips and fixed with $10 \%$ formaldehyde solution. Fixed cells were incubated in blocking solution $(0.1 \%$ Triton $\mathrm{X}-100,0.2 \%$ bovine serum albumin [BSA], and $10 \%$ normal goat serum in PBS) for 30 min at $37^{\circ} \mathrm{C}$ and further incubated in a primary antibody solution (1:100 dilution of antibodies in Can Get Signal immunostaining reagent [TOYOBO]) for $2 \mathrm{~h}$. Next, the cells were washed twice with PBS and incubated in a secondary antibody solution (1:400 dilution of Alexa 488conjugated secondary antibody [Thermo Fisher Scientific] and 1:1000 dilution of Hoechst 33342 [Thermo Fisher Scientific]) in the blocking solution] for $1 \mathrm{~h}$. The cells were again washed twice, mounted on glass slides with Fluoromount (Diagnostic 
384 BioSystems), and observed under an all-in-one fluorescence microscope (BZ-9000;

385 Keyence).

387 Western blotting

388 Western blotting was performed, as previously described (Morita et al., 2018). Briefly, total proteins were extracted from cells with $2 \%$ sodium dodecyl sulfate (SDS) sample buffer. The proteins were electrophoretically separated using $10 \%$ polyacrylamide gels and then transferred to polyvinylidene difluoride membranes. For Western blotting, anti-Arp5 (Proteintech), anti-MyoG (Santa Cruz Biotechnology, Inc.), anti-MyoD

393 (Santa Cruz Biotechnology, Inc.), anti-MYF6 (Santa Cruz Biotechnology, Inc.), anti-MHC (Developmental Studies Hybridoma Bank), anti-glyceraldehyde 3-phosphate dehydrogenase (GAPDH) (Thermo Fisher Scientific), anti-FLAG (Sigma-Aldrich), anti-HA (Roche Applied Science), and anti-Myc (Santa Cruz Biotechnology, Inc.) antibodies were used as primary antibodies.

398

\section{Real-time RT-PCR}

400 Total RNA was isolated and then reverse-transcribed using RNAiso Plus (TAKARA 401 BIO) and the PrimeScript RT Reagent Kit with gDNA Eraser (TAKARA BIO). 402 Real-time RT-PCR was performed using the THUNDERBIRD SYBR qPCT Mix 403 (TOYOBO) on the Mic real-time PCR cycler (Bio Molecular System). Nucleotide sequences of the primer sets used in this study are listed in Table 1.

\section{Reporter promoter analysis}

407 To examine the promoter activity of human $M Y O G$, the proximal promoter region 
$408(-299 /-1)$ of $M y o G$ was isolated by PCR and inserted into the pGL3-basic vector

409 (Promega). The DNA fragments of PME1 and PME2 in the MyoG promoter region were

410 also amplified and inserted into the pGL3- $\gamma$-actin-TATA vector. These reporter vectors

411 were transfected into cells, together with the pSV- $\beta$ Gal vector (Promega) and the

412 indicated gene expression vectors. After 2 days of transfection, luciferase activity was

413 measured using the Luciferase Assay System (Promega), which was normalized to

$414 \quad \beta$-galactosidase activity.

\section{Co-immunoprecipitation assay}

417 HEK293T cells were transfected with expression vectors to synthesize recombinant 418 proteins. The next day, cells were lysed with $0.5 \%$ NP-40, $10 \%$ glycerol, and protease 419 inhibitor cocktail (Nacalai Tesque) in PBS and gently sonicated. The lysate was 420 centrifuged to remove cell debris and then incubated with Protein G Sepharose Fast 421 Flow (Sigma-Aldrich) for $1 \mathrm{~h}$ at $4{ }^{\circ} \mathrm{C}$ to remove nonspecifically bound proteins. After centrifugation, the cell lysate proteins were mixed in the indicated combinations and incubated with the ANTI-FLAG M2 Affinity Gel (Sigma-Aldrich) or the Anti-HA Affinity Matrix from rat immunoglobulin $\mathrm{G}(\operatorname{IgG})_{1}$ (Sigma-Aldrich) for $2 \mathrm{~h}$ at $4{ }^{\circ} \mathrm{C}$. The beads were washed thrice with $0.5 \%$ NP-40 in PBS, and binding proteins were eluted using SDS sample buffer.

\section{Protein-DNA pull-down assay}

DNA probes for the protein-DNA pull-down assay were generated by PCR using

430 5'-biotinylated primers and then conjugated to Dynabeads M-280 Streptavidin (Thermo

431 Fisher Scientific). The recombinant proteins synthesized in HEK293T cells were 
433 glycerol, and protease inhibitor cocktail (Nacalai Tesque) in PBS for $2 \mathrm{~h}$ at $4^{\circ} \mathrm{C}$. The

434 beads were washed thrice with $0.5 \%$ NP-40 in PBS, and binding proteins were eluted 435 using SDS sample buffer.

\section{ChIP assay}

ChIP assays were performed in WT and Arp5-KO RD cells using the SimpleChIP Plus Enzymatic Chromatin IP Kit (Cell Signaling Technology) according to the manufacturer's instructions. Anti-MyoD, anti-MyoG, anti-Pbx1/2/3/4, and anti-Brg1 antibodies (all from Santa Cruz Biotechnology, Inc.) were used for immunoprecipitation.

\section{DNase I sensitivity assay}

DNase I sensitivity assays were performed, as previously reported with slight modifications (Gerber et al., 1997). Briefly, WT and Arp5-KO RD cells were suspended in $0.5 \% \mathrm{NP}-40,10 \mathrm{mM} \mathrm{NaCl}, 5 \mathrm{mM} \mathrm{MgCl} 2$, and Tris- $\mathrm{HCl}$ at $\mathrm{pH} 7.4$ for $10 \mathrm{~min}$ at $4^{\circ} \mathrm{C}$ to isolate the nuclei. After centrifugation, the pelleted nuclei were resuspended in DNase I buffer $\left(10 \mathrm{mM} \mathrm{NaCl}, 6 \mathrm{mM} \mathrm{MgCl} 2,1 \mathrm{mM} \mathrm{CaCl}_{2}\right.$, and $40 \mathrm{mM}$ Tris- $\mathrm{HCl}$ at $\mathrm{pH}$ 8.0) and then treated with $1.5 \mathrm{U} / 50 \mathrm{~mL}$ of DNase I (Thermo Fisher Scientific) for $10 \mathrm{~min}$ at $37^{\circ} \mathrm{C}$.

451 The reaction was stopped by adding an equal volume of $40 \mathrm{mM}$ ethylenediaminetetraacetic acid (EDTA). The digested nuclei were collected by centrifugation, suspended in $50 \mathrm{mM} \mathrm{NaOH}$, and heated for $10 \mathrm{~min}$ at $100^{\circ} \mathrm{C}$ to extract DNA. The resulting solution was diluted 100 times with TE (1 mM EDTA, $10 \mathrm{mM}$ 
456 genes was calculated by comparing the amount of intact enhancer fragments between

457 DNase-I-treated and DNase-I-untreated samples using real-time PCR.

DNA microarray

460 Total RNAs were isolated from RD cells transfected with control, Arp5, Ies6, and Ino80 siRNA for 2 days, using NucleoSpin RNA Plus (TAKARA BIO). mRNAs were reverse-transcribed, and Cy3-labeled complementary RNAs (cRNAs) were synthesized using the Low Input Quick Amp Labeling Kit (Agilent Technologies). The cRNAs were hybridized on a SurePrint G3 Mouse Gene Expression $8 \times 60 \mathrm{~K}$ Microarray (Agilent Technologies), and fluorescence signals were detected using the SureScan Microarray Scanner (Agilent Technologies). The fluorescence intensity was quantified using Feature Extraction Software (Agilent Technologies).

Statistics and reproducibility

470 All statistical data were generated from experiments independently repeated at least three times, and values were expressed as the mean \pm standard error of the mean (SEM). considered statistically significant.

\section{Data statement}

DNA microarray data have been deposited in the Gene Expression Omnibus (GEO) 


\section{Competing Interest Statement}

481 The authors declare no conflicts of interest associated with this manuscript.

\section{Acknowledgments}

484 We thank all the staff in the Laboratory Animal Center, Wakayama Medical University and the Center for Medical Research and Education of Osaka University Graduate

School of Medicine for their technical assistance. We also thank Enago (www.enago.jp) for the English language review. This work was supported by JSPS KAKENHI Grant

Number 15K07076 (to T. Morita), 18K06913 (to T. Morita) and 19K07351 (to K. 489 Hayashi).

\section{References}

Berkes CA, Bergstrom DA, Penn BH, Seaver KJ, Knoepfler PS, Tapscott SJ (2004) Pbx marks genes for activation by MyoD indicating a role for a homeodomain protein in establishing myogenic potential. Mol Cell 14: 465-477. doi: 

10.1002/dvdy.24217.

Davis RL, Weintraub H, Lassar AB (1987) Expression of a single transfected cDNA

doi:

de la Serna IL, Carlson KA, Imbalzano AN (2001) Mammalian SWI/SNF complexes $10.1038 / 84826$.

de la Serna IL, Ohkawa Y, Berkes CA, Bergstrom DA, Dacwag CS, Tapscott SJ, Imbalzano AN (2005) MyoD targets chromatin remodeling complexes to the myogenin locus prior to forming a stable DNA-bound complex. Mol Cell Biol 25: 3997-4009. doi: 10.1128/MCB.25.10.3997-4009.2005.

Folpe AL (2002) MyoD1 and myogenin expression in human neoplasia: a review and update. $A d v$ Anat Pathol

9: 198-203.

doi: 10.1097/00125480-200205000-00003.

Funk WD, Ouellette M, Wright WE (1991) Molecular biology of myogenic regulatory factors. Mol Biol Med 8: 185-195.

Funk WD, Wright WE (1992) Cyclic amplification and selection of targets for multicomponent complexes: myogenin interacts with factors recognizing binding sites for basic helix-loop-helix, nuclear factor 1, myocyte-specific enhancer-binding factor 2, and COMP1 factor. Proc Natl Acad Sci U S 89: 9484-9488. doi: 10.1073/pnas.89.20.9484.

525 Gerber AN, Klesert TR, Bergstrom DA, Tapscott SJ (1997) Two domains of MyoD 
mediate transcriptional activation of genes in repressive chromatin: a mechanism for lineage determination in myogenesis. Genes Dev 11: 436-450. doi: 10.1101/gad.11.4.436.

Haldar M, Hancock JD, Coffin CM, Lessnick SL, Capecchi MR (2007) A conditional mouse model of synovial sarcoma: insights into a myogenic origin. Cancer Cell 11: 375-388. doi: 10.1016/j.ccr.2007.01.016.

Halevy O, Novitch BG, Spicer DB, Skapek SX, Rhee J, Hannon GJ, Beach D, Lassar AB (1995) Correlation of terminal cell cycle arrest of skeletal muscle with induction of p21 by MyoD. Science 267: 1018-1021. doi: 10.1126/science.7863327. homeodomain proteins mediates Hoxb2 hindbrain enhancer activity. Mol Cell

Keller C, Guttridge DC (2013) Mechanisms of impaired differentiation in rhabdomyosarcoma. FEBS J 280: 4323-4334. doi: 10.1111/febs.12421. SJ, Kamps MP (1999) A conserved motif N-terminal to the DNA-binding domains of myogenic bHLH transcription factors mediates cooperative DNA 

3763. doi: 10.1093/nar/gkv194.

Lee SY, Obata Y, Yoshida M, Stockert E, Williamson B, Jungbluth AA, Chen YT, Old LJ, Scanlan MJ (2003) Immunomic analysis of human sarcoma. Proc Natl Acad Sci U S A 100: 2651-2656. doi: 10.1073/pnas.0437972100.

Lu J, McKinsey TA, Zhang CL, Olson EN (2000) Regulation of skeletal myogenesis by association of the MEF2 transcription factor with class II histone deacetylases. Mol Cell 6: 233-244. doi: 10.1016/s1097-2765(00)00025-3.

Morita T, Hayashi K (2014) Arp5 is a key regulator of myocardin in smooth muscle cells. J Cell Biol 204: 683-696. doi: 10.1083/jcb.201307158.

Nakka K, Ghigna C, Gabellini D, Dilworth FJ (2018) Diversification of the muscle proteome through alternative splicing. Skelet Muscle 8: 8 . doi: $10.1186 / \mathrm{s} 13395-018-0152-3$

Nasif S, Contu L, Mühlemann O (2018) Beyond quality control: The role of nonsense-mediated mRNA decay (NMD) in regulating gene expression. Semin AN (2007) Myogenin and the SWI/SNF ATPase Brg1 maintain myogenic gene expression at different stages of skeletal myogenesis. $J$ Biol Chem 282: 6564-6570.

Poli J, Gasser SM, Papamichos-Chronakis M (2017) The INO80 remodeller in transcription, replication and repair. Philos Trans $R$ Soc Lond B Biol Sci 372: 20160290. doi: 10.1098/rstb.2016.0290.

Puri PL, Sartorelli V, Yang XJ, Hamamori Y, Ogryzko VV, Howard BH, Kedes L, Wang 

PCAF acetyltransferases in muscle differentiation. Mol Cell 1: 35-45. doi: 10.1016/s1097-2765(00)80005-2.

577 Roy K, de la Serna IL, Imbalzano AN (2002) The myogenic basic helix-loop-helix 578 family of transcription factors shows similar requirements for SWI/SNF chromatin remodeling enzymes during muscle differentiation in culture. $J$ Biol Chem 277: 33818-33824. doi: 10.1074/jbc.M205159200.

Schroer TA (1999) Actin-related proteins. Annu Rev Cell Dev Biol 15: 341-363.

Shen X, Mizuguchi G, Hamiche A, Wu C (2000) A chromatin remodelling complex involved in transcription and DNA processing. Nature 406: 541-544. doi: $10.1038 / 35020123$.

Tapscott SJ (2005) The circuitry of a master switch: Myod and the regulation of skeletal muscle gene transcription. Development 132: 2685-2695. doi: 10.1242/dev.01874. Assembly of the Arp5 (Actin-related Protein) Subunit Involved in Distinct INO80 Chromatin Remodeling Activities. J Biol Chem 290: 25700-25709. doi: 10.1074/jbc.M115.674887.

593 INO80 Complex Requires the Arp5-Ies6 Subcomplex for Chromatin 594 Remodeling and Metabolic Regulation. Mol Cell Biol 36: 979-991. doi: 10.1128/MCB.00801-15.

596 Yuan W, Condorelli G, Caruso M, Felsani A, Giordano A (1996) Human p300 protein is a coactivator for the transcription factor MyoD. $J$ Biol Chem 271: 9009-9013. 
bioRxiv preprint doi: https://doi.org/10.1101/2021.05.27.446008; this version posted May 27, 2021. The copyright holder for this preprint (which was not certified by peer review) is the author/funder, who has granted bioRxiv a license to display the preprint in perpetuity. It is made available under aCC-BY 4.0 International license.

$598 \quad$ doi: $10.1074 /$ jbc.271.15.9009.

599 Zhou C, Zou J, Zou S, Li X (2016) INO80 is Required for Osteogenic Differentiation

600 of Human Mesenchymal Stem Cells. Sci Rep 6: 35924. doi: 10.1038/srep35924. 